\title{
Equity Trading and the Allocation of Market Data Revenue*
}

\author{
Cecilia Caglio \\ Federal Reserve Board of Governors \\ 20th Street and Constitution Avenue, NW \\ Washington, DC 20551 \\ cecilia.r.caglio@frb.gov \\ (202) 452-3084 \\ Stewart Mayhew \\ Cornerstone Research \\ 1919 Pennsylvania Avenue, NW \\ Suite 600 \\ Washington, DC 20006 \\ smayhew@cornerstone.com
}

(202) 912-8960

July 23, 2012

\footnotetext{
${ }^{*}$ We would like to thank Daniel Aromi, Tom Dowling, David Goldreich, Dan Gray, Kathleen Hanley, Tim McCormick, Lois Lightfoot, Marc Lipson, Jonathan Sokobin, Josh White, Stephen Williams, and seminar participants at the 2008 WFA meeting, the 2008 EFA meeting, 3rd annual Conference on Market Structure and Market Integrity, Securities and Exchange Commission, Lancaster University and University of Missouri. The views expressed in this paper are solely the responsibility of the authors and should not be interpreted as reflecting the views of the Board of Governors of the Federal Reserve System, any other person associated with the Federal Reserve System, or Cornerstone Research. Part of this research was conducted while the authors were employed at the Securities and Exchange Commission.
} 


\title{
Equity Trading and the Allocation of Market Data Revenue
}

\begin{abstract}
Revenues generated from the sales of consolidated data represent a substantial source of income for U.S. stock exchanges. Until 2007, consolidated data revenue was allocated in proportion to the number of reported trades. This allocation rule encouraged market participants to break up large trades and execute them in multiple pieces. Exchanges devised revenue-sharing and rebate programs that rewarded order-flow providers, and encouraged algorithmic traders to execute strategies involving large numbers of small trades. We provide evidence that data revenue allocation influenced the trading process, by examining trading activity surrounding various events that changed the marginal data revenue per trade.
\end{abstract}


Data revenue constitutes an important source of income for securities exchanges. For example, sales of consolidated equity market data in the United States generated approximately $\$ 400$ Million in 2004, representing about 10-15\% of total revenues reported by the largest exchanges, and substantially more for some of the smaller exchanges. By 2008, consolidated data sales revenue had increased to approximately $\$ 450$ Million. ${ }^{1}$ In the U.S., the process of collecting and disseminating quote data is managed by a set of industry "Plans." ${ }^{2}$ These Plans also oversee the collection of fees charged for access to the consolidated data networks, and the allocation of the resulting revenue across the member exchanges.

Market structure in U.S. equity markets and the competitive structure of the industry have been in a state of dynamic evolution since the reforms of the late 1990s, and in particular since the passage of Regulation NMS in 2005. Among the most significant of these developments are the consolidation of ownership of the historic exchanges into a few large international groups, ${ }^{3}$ the growth of Electronic Communications Networks (ECNs) and their subsequent mergers with or conversion to registered stock exchanges, ${ }^{4}$ and the movement of the industry to a "make or take" fee structure.

A complete understanding of the economic forces driving this revolution must include an analysis of market data revenues, how these revenues are allocated across exchanges, and how the allocation mechanism might favor particular market structures in equilibrium.

\footnotetext{
${ }^{1}$ Data on aggregate consolidated data revenues are not publicly available, but were reported for 2004 and 2008 in Securities and Exchange Commission releases. See Securities and Exchange Commission, Regulation NMS Adopting Release, No. 34-51808, June 9, 2005, and Concept Release on Equity Market Structure, No. 34-61358, April 21, 2010, and the Exchanges' public financial statements.

${ }^{2}$ For securities listed on NYSE, AMEX, and other exchanges besides Nasdaq, data distribution is governed by The Consolidated Tape Association Plan (CTA) and the Consolidated Quotation Plan (CQ), which were created in the 1970s. For Nasdaq securities, data distribution is governed by the Nasdaq UTP Plan(UTP), created in 1990.

${ }^{3}$ NYSE Euronext owns the NYSE and the exchanges formerly known as the AMEX and ARCA (owner of the original Pacific Exchange license); Nasdaq OMX Group owns Nasdaq, and the exchanges formerly known as the Boston Stock Exchange and the Philadelphia Stock Exchange.

${ }^{4}$ For example, Instanet merged with Island ECN and was acquired by Nasdaq, BRUT ECN was aquired by Nasdaq, Archipelago ECN became an exchange by acquiring the Pacific Exchange, BATS ECN registered as an exchange, and Direct Edge ECN registered as an exchange.
} 
In this paper, we take a step in this direction by documenting that the allocation of data revenue can impact investors' decisions of how and where execute and report a trade.

The formula used under the CTA plan until April 1, 2007 allocated revenue in proportion to the number of (round-lot) trades reported by each exchange. By linking revenue to trade reports, the allocation rule created an incentive for exchanges to pay for directed order flow, to enter into arrangements with brokers or ECNs to print trades that were executed off-exchange, and eventually to merge with ECNs.

In addition, this allocation formula assigned twice as much revenue for two trades of 100 shares than one of 200 shares. This created a situation where exchanges received more revenue when large orders were broken up and executed in multiple small pieces. Beginning in 1997, some of the exchanges implemented revenue-sharing or rebate programs, that created an incentive for brokers to split their customers' orders, and for proprietary traders to engage in algorithmic trading designed solely to capture the rebates. ${ }^{5}$

In this paper, we show that the original allocation formula created incentives that influenced the trading process. In particular, we demonstrate that average trade size is sensitive to changes in the marginal revenue per trade. Our evidence indicates that the distortive impact of the allocation rule is not spread evenly across all securities, but is concentrated in certain securities. We also find evidence that rebate programs were a key institutional mechanism through which the allocation rule influences the trading process.

Our analysis has four prongs. First, on December 1, 2004 the Nasdaq 100 Index Tracking Stock (QQQ) moved its listing from AMEX to Nasdaq. Prior to the move, QQQ accounted for more than $40 \%$ of the trades on Network B. When these trades were removed, this increased the revenue per trade for those securities remaining in Network B. This event allows us to examine the effects of a change in incentives without the possibility of contamination from other factors associated with a security changing its primary listing venue. We find that when QQQ left, average trade size decreased for those securities remaining in Network B,

\footnotetext{
${ }^{5}$ For example, see the case involving MarketXT, Inc. SEC Administrative Proceeding File no. 3-11813.
} 
particularly on those exchanges that had rebate programs.

Second,we examine trading activity for a sample of 40 Exchange Traded Funds (ETFs) that switched primary listing from the American Stock Exchange (AMEX) to the New York Stock Exchange (NYSE) on November 30, 2005. The effect of this move was immediate and striking. Comparing the three-month periods before and after the switch, we find that average trade size increased by more than a factor of five. Average trade size increased on all the exchanges but the extreme magnitude of the result was largely driven by changes in trading activity on exchanges with aggressive rebate programs. We also study the effect of this move on the stocks that remained listed on AMEX. As was the case for the QQQ migration, we again find evidence that average trading size decreased and the proportion of 100-share trades increased for the stocks remaining in Network B.

Third, between August 2005 and May 2006, six exchanges and the National Association of Securities Dealers (NASD) adopted "Tape Shredding" rules prohibiting brokers from breaking up customer orders into smaller pieces for any reason other than best execution. However, these rules place no restrictions on the actions of proprietary trading desks. By looking at the impact of these rules, we can evaluate the extent by which the breaking up of large orders into small orders is driven by broker agency trading, as opposed to proprietary trading. For the exchanges most involved in trading Network B securities, these rule changes went into effect in April and May of 2006. We examine whether these rules had any observable effect on average trade size. When we aggregate across securities, we find a sudden, economically large increase in average size of Network B trades on Nasdaq and NYSE Arca, both of which had rebate programs, but a decrease in average trade size on AMEX, which did not have a rebate program. This result disappears when securities are equally weighted in a paired t-test, confirming that tape shredding activity was concentrated in a relatively small number of securities. For Network A securities, where revenue per trade was lower, we find no significant increases in average trade size when these tape-shredding rules went into effect. 
Fourth, the Securities and Exchange Commission (SEC) established a new allocation formula at the same time it adopted Regulation NMS, under which only one fourth of the revenue is allocated in proportion to the number of trades. ${ }^{6}$ When the new formula went into effect on April 1, 2007, there was an immediate decrease in the marginal revenue allocated to an exchange as a result of splitting trades. However, there was no immediate change in the terms of the exchanges' rebate programs. Consistent with our earlier results for Network B securities, we find a statistically significant increase in average trade size on NYSE Arca, and a decrease on AMEX. Again, no significant increases in trade size were observed on Network A securities.

It has long been believed by industry participants and regulators that allocation formulas influence how trades are executed and reported. To the best of our knowledge, this paper provides the first comprehensive academic study of this topic. It confirms that the incentives created by allocation formulas are large enough to have a significant impact on average trade size, that revenue-sharing/rebate programs are a key mechanism used by the exchanges to align the incentives of order-flow providers with the exchange, and that distortive impact of the old allocation formula was significantly larger in Network B than in Network A.

Our results should be of interest to exchanges and regulators around the world, as they consider approaches to market data, and broader questions such as the extent to which market data should be considered a public good, whether and to what extent the distribution of market data should be consolidated across exchanges, and how property rights to market data should be assigned. Among the prior authors who have focused on these issues are Mulherin, Netter, and Overdahl (1991), and Boulatov and Dierkir (2007).

Our research also contributes directly or indirectly to several other areas of academic research. For example, we introduce a new dimension to the analysis of competition between exchanges, other aspects of which have been considered by authors such as Arnold, Hersh, Mulherin, and Netter (1998), Santos and Scheinkman (2001), Bessembinder (2003), Foucault

\footnotetext{
${ }^{6}$ See SEC Release No. 34-51818, June 9, 2005.
} 
and Parlour (2004) and Caglio and Pescatori (2012). Our results have immediate implications for the "Stealth Trading" literature, which implicitly assumes the main motivation to break up larger trades into smaller trades is to camouflage informed trading (see Barclay and Warner (1993), Chakravarty (2001), Choe and Hansch (2006)). Market data rebate programs have a direct influence on the large investor's tradeoff between block trading and "working" an order, a topic addressed by authors such as Seppi (1990), Cheng and Madhavan (1997), and Back and Baruch (2007).

In addition, we would argue that market data revenue is an impetus contributing to the practices of payment for order flow, internalization, order preferencing, and make-or-take fees, but has largely been ignored in the literature investigating those practices. Among the many authors who have studied these topics are Chordia and Subrahmanyam (1995), Battalio, Green, and Jennings (1998), Bloomfield and O'Hara (1998), Battalio and Holden (2001), Parlour and Rajan (2003), Peterson and Sirri (2003), Chung, Chuwonganant, and McCormick (2004), Foucault, Kadan, and Kendel (2011).

This paper is organized as follows. In section I we provide an overview of the regulatory history of the Plans that administer the dissemination of consolidated market data. We discuss the formulas used to allocate revenues, describe the revenue-sharing or rebate plans used by the exchanges to compete for trade prints, and give several examples of how revenue allocation has been influenced by trade reporting arrangements or mergers between ECNs and Exchanges. Section II investigates how the migration of the Nasdaq 100 tracking stock from Network B to Network C affected the trading patterns for those stocks remaining in Network B. Section III contains our analysis of 40 ETFs that switched from AMEX to NYSE on November 30, 2005. Section IV reports our analysis of the tape shredding rules implemented by the exchanges in 2005 and 2006. In section V we report our results on the impact of the new Revenue Allocation rule that went into effect on April 1, 2007. Section VI provides additional commentary and concludes the paper. 


\section{Institutional Background}

\section{A Consolidated Data Plans and Revenue Allocation}

The regulatory framework for the dissemination of real-time consolidated last sale and quote data from U.S. Equity markets is set forth in three plans, the CTA Plan, the CQ Plan, and the UTP Plan. ${ }^{7}$ These Plans are administered by their participants, who are registered National Securities Exchanges or National Securities Associations, and overseen by the SEC. As of September 2007, the parties to the CTA, CQ, and UTP Plans included eleven participants. ${ }^{8}$

Under these Plans, eligible securities are assigned to one of three Networks based on where the security is listed. Securities listed on NYSE are assigned to Network A, those listed on another National Securities Exchange but not NYSE or Nasdaq are assigned to Network B. Networks A and B are administered by the CTA Plan and CQ Plan. The UTP Plan administers the dissemination of market data for Nasdaq Global Market and Nasdaq Capital Market securities that are not part of Networks A and B. We will refer to this distribution channel as "Network C."

Market data revenues amount to hundreds of millions of dollars annually, and represent a nontrivial portion of the exchanges' total revenues. For example, in 2004, Networks A, B, and $\mathrm{C}$ generated net income of approximately $\$ 155$ Million, $\$ 100$ Million, and $\$ 138$ Million, respectively, for a total of approximately $\$ 394$ Million. ${ }^{9}$ For most of the exchanges, market data revenues constitute somewhere between $10 \%$ and $20 \%$ of total revenues.

Tape Revenue is allocated across market centers according to formulas established under the regulatory jurisdiction of the SEC. Prior to April 1, 2007, revenue on Networks A and $\mathrm{B}$ was allocated in proportion to the number of round-lot transactions reported by the

\footnotetext{
${ }^{7}$ A separate plan governs dissemination of options data, under the Options Price Reporting Authority.

${ }^{8}$ American Stock Exchange (AMEX), Boston Stock Exchange, Chicago Board Options Exchange, Chicago Stock Exchange (CHX), International Securities Exchange, Nasdaq Stock Market, National Association of Securities Dealers (NASD), National Stock Exchange (formerly Cincinnati Stock Exchange), New York Stock Exchange, NYSE Arca (formerly Pacific Exchange), and Philadelphia Stock Exchange.

${ }^{9}$ Regulation NMS Adopting Release, Securities and Exchange Commission Release No. 34-51808, June $9,2005$.
} 
Participant. Revenue on Network $\mathrm{C}$ was allocated half in proportion to the number of transactions and half in proportion to share volume.

In conjunction with the adoption of Regulation NMS, the SEC in June 2005 adopted a new allocation formula for the various plans. The new formula was originally scheduled to go into effect on September 1, 2006, but was delayed to April 1, 2007. The new algorithm (1) associates revenues with individual securities in proportion to the square root of dollar trading volume, and (2) allocates revenues across exchanges one fourth in proportion to the number of trades, one fourth in proportion to dollar volume, and one half in proportion to the degree to which the exchange's quotes contribute to the National Best Bid and Offer (NBBO). The main effect of the square root transformation is to spread the revenue more evenly across securities. The effect of the weighted allocation function is to reduce the incentive for tape shredding and to create an additional incentive for exchanges to provide liquidity at the NBBO.

\section{B Revenue Sharing/Rebate Programs}

In the late 1990s, exchanges began to introduce programs to share data revenue with the specialists or member firms that generated the order flow. When an exchange shares data revenue with member firms in proportion to how much revenue they generate, this creates an incentive to execute large orders in smaller pieces.

Between 1997 and 1999, revenue sharing or rebate programs were initiated by three regional exchanges and Nasdaq. Specifically, programs were introduced by the Chicago Stock Exchange (CHX), effective January 17, 1997, ${ }^{10}$ Cincinnati Stock Exchange (CSE), effective November 13, 1997, ${ }^{11}$ Boston Stock Exchange (BSE), effective October 1, 1998, ${ }^{12}$ and Nasdaq, effective March 4, $1999 .^{13}$

The specifics of these programs differed across exchanges. For example, on CHX, rebates

\footnotetext{
${ }^{10}$ Securities Exchange Act Release No. 38237 (February 4, 1997), 62 FR 6592.

${ }^{11}$ Securities Exchange Act Release No. 39395 (December 3, 1997), 62 FR 65113.

${ }^{12}$ Securities Exchange Act Release No. 40591 (October 22, 1998), 63 FR 58078.

${ }^{13}$ Securities Exchange Act Release No. 41174 (March 16, 1999), 64 FR 14034.
} 
were computed on a stock-by-stock basis, according to the specialist's monthly market share in that particular stock. Specialists received a rebate of $18 \%$ for all trades up to a market share of $7 \%, 36 \%$ for trades in excess of $7 \%$ and up to $12 \%$ market share, and $54 \%$ for trades above $12 \%$ of market share. Under the CSE program, members were credited on a pro rata basis, based upon the percentage of Network B transaction market share captured by the exchange in a given quarter, rebating 10\% of revenues for stocks in which the CSE market share was below $3 \%, 25 \%$ when the market share was between $3 \%$ and $5 \%, 30 \%$ when the market share was between $5 \%$ and $7 \%$, and $40 \%$ when the market share was at least $7 \%$. The BSE revenue sharing program rebated $50 \%$ of consolidated Tape A and Tape B market data revenue, and the Nasdaq program offered rebates from pools made of $40 \%$ of Tape A and B revenues. These descriptions apply to the revenue-sharing programs as initially designed, but the programs have been modified numerous times over the years.

On May 28, 2002, the Pacific Exchange (PCX), after its equity trading business had been taken over by Archipelago, implemented a revenue-sharing program targeted to trades executed on the Archipelago Exchange. In June, 2002, PCX, Nasdaq and CSE expanded their revenue sharing programs, but the Securities and Exchange Commission abrogated these fee changes on July 2, 2002. The PCX reinstated its revenue-sharing programs through rule filings on July 9, 2002 for Network B securities, and on August 6, 2002 for Network A securities. ${ }^{14}$ This program evolved over the years, as PCX completed its merger with Archipelago, and then was taken over by the NYSE. After the merger, NYSE Arca continued to have a rebate program. While this program had some limitations on who is eligible to receive rebates, the amount of the pool for calculation purposes was based on $50 \%$ of the gross revenues derived from market data fees. The rebate program established a 50\% transaction credit on revenues generated by Network A non-ETF securities and Network B securities, while the Network $\mathrm{C}$ program was based on a pro rata contribution of the operating revenues generated by each participant.

\footnotetext{
${ }^{14}$ Securities Exchange Act Release No. 46293.
} 


\section{Reporting Arrangements and Platform Mergers}

Trading platforms that are not National Securities Exchanges are not eligible to participate directly in the consolidated revenue plans. However, trades executed on these platforms are reported through a participant exchange, or a trade-reporting facility connected to a participant. For example, trades executed on ECNs generate market data revenue for the exchange on which the ECN chooses to report. In cases where an ECN is able to attract a significant market share, the data revenue attached to those trades make the ECN particularly attractive to the exchanges, and vice versa. This synergy created an impetus for revenue sharing arrangements between exchanges and ECNs, and increased the attractiveness of mergers between exchanges and ECNs.

For example, arrangements between Island (later iNet) and the Cincinnati Stock Exchange in 2002 generated substantial Network B and Network C revenues for that exchange, until iNet was acquired by Nasdaq in December 2005. Archipelago ECN was able to access data revenue by aligning with the Pacific Exchange. Archipelago aligned with the Pacific Exchange in 2000, registered as a stock exchange and became Arca Ex in 2001, migrated all PCX equity trading to Arca Ex in 2002, and began to report trades via the Pacific Exchange in stages between 2002 and 2003. Arca Ex took over the Pacific Exchange completely in 2005, only to be acquired by NYSE in March 2006.

Figures 1 and 2 illustrate the extent to which these reporting arrangements and acquisitions influenced the distribution of trade prints across exchanges. Figure 1 graphs the market share of Network B trades (computed from TAQ data) for AMEX, Cincinnati/National Stock Exchange, PCX/Arca, and Nasdaq, from 2001 to 2006. For clarity, daily fluctuations are smoothed using a 5-day moving average. The impact of the trade-reporting arrangement between the Cincinnati Stock Exchange and Island ECN may be easily observed in July 2002. Likewise, market share immediately transferred from Cincinnati (National) to Nasdaq in January 2006 following Nasdaq's acquisition of iNet. Particularly striking in this figure is the experience of Arca Ex and the Pacific Exchange, which went 
from almost zero to in excess of $50 \%$ market share of Network B in two years.

[ Figure 1 here ]

Figure 2 shows a similar graph for Network C. This figure graphs the market share of Network C trades, computed from TAQ), for Nasdaq, Cincinnati/National, PCX/Arca, and The Boston Stock Exchange, from 2001 to 2006. Cincinnati's Network C market share went from zero to nearly $20 \%$ overnight on March 18, 2002 when Island began reporting trades there, and jumped up again in February 2004 when Instinet moved its trade reporting from NASD's Alternative Display Facility to Cincinnati. Likewise, the market share of trades reported by the Pacific Exchange increased from essentially zero to nearly $20 \%$ when Arca Ex began reporting its Network C trades there in April 2003. The graphs also shows the impact of an arrangement between the BRUT ECN and the Boston Stock Exchange in December 2003, and the acquisition of the BRUT ECN by Nasdaq in September 2004.

[ Figure 2 here ]

\section{Migration of the Nasdaq-100 Tracking Stock}

On December 1, 2004 primary listing of the Nasdaq 100 Index Tracking Stock (QQQ) moved from AMEX to Nasdaq. Before this change, QQQ accounted for a substantial proportion of the trades on Network B. For example, based on the TAQ data, we estimate that in the three months from September through November, 2004, QQQ accounted for approximately $45.7 \%$ of trades reported on Network B.

Evidence that tape shredding was occurring on the QQQ prior to its departure from AMEX has been provided by Kugele and Wood (2006). Analysis of this event is somewhat complicated by differences in market microstructure between AMEX and Nasdaq, and by the fact that the CTA allocation formula was different from the UTP formula. For these reasons, we do not conduct of formal analysis of changes in the QQQ itself. We merely note that average trade size in the QQQ more than doubled when it migrated to Nasdaq, as 
illustrated by Figure 3. Casual examination of trading patterns on the individual exchanges surrounding December 1, 2004 indicates a particularly dramatic increase in the average trade size on Arca Ex and on the Chicago Stock Exchange.

[ Figure 3 here ]

Our analysis focuses on how the departure of the QQQ affected trading in those stocks remaining in Network B. After the migration, QQQ trades no longer claimed Network B revenue, and this increased the revenue allocated to trades on the remaining securities. In the absence of any equilibrating response by market participants, this would have raised the marginal revenue per trade on the remaining Network B securities by more than $80 \%$. If the market responded to this change in incentives, we would expect to see more tape shredding in other Network B securities after the departure of the QQQ.

Tests involving direct examination of securities that switch exchanges may be influenced by other confounding effects. For example, there may be differences between the two exchanges that affect trading patterns, or the choice of the issuer to move its listing may have been influenced by endogenous factors that are also related to trading activity. Such concerns should not arise when we examine those securities that do not migrate.

In order to investigate how the departure of the QQQ affected the other Network B stocks, we extract trade data for all AMEX listed stocks from the NYSE trade and quote (TAQ) database from September 2004 to February 2005. We eliminated from consideration three stocks that moved from AMEX to NYSE during this period. We examine trading activity of Network B stocks on each exchange, only considering those stocks that continue to trade on the same exchange before and after the QQQ migration. Table I reports the number of trades, total volume, and average trade size for Network B stocks before and after December 1, 2004.

[Table I here] 
As indicated in the table, all the exchanges except Philadelphia experienced a statistically significant increase in daily trading volume of Network B stocks after QQQ left AMEX. And all except AMEX and Philadelphia experienced significant increases in the number of trades. Nasdaq, Arca Ex, Chicago, and National experienced significant declines in average trade size. Of particular note, average trade size declined the most on Arca Ex (-31\%) and Chicago (-17\%)-the same exchanges that experienced the largest increase in trade size on the QQQs.

Table II shows the distribution of trade sizes on Network B stocks on each exchange before and after the migration. It shows the percentage of reported trades in each of six size buckets, including trades of 100 shares, trades between 101 and 499 shares, trades between 500 and 999 shares, trades between 1000 and 2499 shares, and trades above 2500 shares. We find an economically important increase in the proportion of 100-shares trades on ARCA Ex and the regional exchanges. For example, the proportion of 100-share trades on the remaining Network B stocks increased from approximately $24 \%$ to $35 \%$ on Nasdaq, $74 \%$ to $84 \%$ on Arca Ex, $23 \%$ to $39 \%$ on Chicago, and $25 \%$ to $58 \%$ on National. This confirms that the changes in mean are largely driven by the changes in the number of small trades, not by changes in the number of block trades.

\section{[Table II here]}

The results in Tables I and II provide evidence of tape shredding in Network B securities, and in particular that the amount of tape shredding is sensitive to the marginal revenue to per trade. To further explore whether tape shredding is confined to a certain type of securities, we partitioned our sample in various ways and repeated our analysis. In the interest of space, we do not include numeric results here, but we find that among the securities remaining on Network B, the significant changes in average trade size are observed for both ETFs and nonETFs. ${ }^{15}$ The evidence of tape shredding appears to be stronger for higher-volume securities, but is not confined to only the top decile or even the top half of securities. There appears to be no obvious relation between tape shredding and price level.

\footnotetext{
${ }^{15}$ We obtain the list of ETFs from the archived issues of ETFR on www.indexuniverse.com.
} 
Inasmuch as a relatively small number of very large block trades can have a big impact on average trade size, as a robustness check we repeated our analysis throwing out all block trades of over 10,000 shares. We found that our results were qualitatively unchanged (results not reported).

\section{Securities Switching from AMEX to NYSE}

In the previous section, we examined changes in trading patterns surrounding the migration of the QQQ from AMEX to Nasdaq. However, we did not formally examine changes in trading patterns on the QQQ itself, in part because we believed it would be hard to disentangle the effects of tape shredding from the effects of changing the primary listing from a specialist structure to a dealership structure. It is well-known that trades are reported differently on the specialist exchanges and Nasdaq, making direct comparisons difficult. Furthermore, the analysis of the change in marginal incentive to split large trades into small trades is complicated by the fact that CTA and UTP plans used different allocation formulas.

However, securities migrating from AMEX to NYSE remain within CTA, within a specialist market structure, and the primary listing remained with an exchange that did not have a rebate program. Although there are some differences between NYSE and AMEX, we believe for the purposes of isolating the effects of a change in marginal revenue per trade, a move from AMEX to NYSE is a cleaner natural experiment than is a move from AMEX to Nasdaq.

As mentioned before, market data revenues are collected and allocated separately for NYSE-listed ("Network A") and AMEX-listed ("Network B") securities. Based on numbers for calendar year 2004, the aggregate data revenue was almost 50\% higher for Network A than for Network B. But because the number of trades for Network A was more than ten times higher than for Network B, revenue per trade was substantially higher for stocks with their primary listing on AMEX than those with their primary listing on NYSE. For 2004, we 
estimate that market data revenue amounted to approximately $\$ 0.15$ per trade on Network A and $\$ 1.03$ per trade on Network B. Thus, when a security moved its primary listing from AMEX to NYSE, the marginal benefit of splitting a large trade into multiple small trades declined significantly. If market participants responded to these incentives, we would expect the average trade size to increase when the security migrated.

We test this hypothesis by examining sample of 40 Exchange Traded Funds (ETFs) that switched from AMEX to NYSE on November 30, 2005. In 2005, Barclays Global Investors (BGI) announced that the primary listing for 81 iShares ETFs would move off of the American Stock Exchange, some to NYSE and some to ARCA. As a result of this move, those ETFs moving to the NYSE would change from trading in Network B to Network A, while those moving to ARCA would remain in Network B. As the first phase of this migration, BGI moved 40 iShares ETFs from AMEX to NYSE on November 30, 2005. These included ETFs tracking large-cap, mid-cap, and small-cap indexes, value and growth component indexes, sector indexes, and international equity indexes.

Analysis of this event is somewhat contaminated by a confounding event. Having been purchased by Nasdaq, iNet ECN stopped reporting its trades on National and began reporting them on Nasdaq during the first week of January 2006. This caused a sudden change in the composition of trades reported on those two exchanges. Accordingly, we exclude these two exchanges from our examination of three-month event windows before and after the migration. To compensate, we perform additional analysis based on one-month event windows, which are short enough to exclude the confounding event in January.

\section{[Table III here]}

Our results are reported in Table III, with Panel A reporting events based on threemonth windows and Panel B reporting results on one-month windows. Not surprisingly, NYSE gained and AMEX lost market share when the primary listing switched. Consistent with the sudden decrease in the benefit of tape shredding, we find a large increase in average trade size on all the exchanges not directly involved with the listing change. Based on the 
three-month window, we observe significant increases in average trade size on the Chicago and Boston exchanges, and a huge increase in the trade size on Arca Ex. As indicated in Panel $\mathrm{B}$, the results based on one-month windows are essentially the same for these exchanges, but also reveal a huge increase in the average trade size on the National Exchange, and a very large increase on Nasdaq. Across all exchanges, average trade size increased by more than 500\%. As shown in Figure 4, this change did not occur gradually over the six-month period surrounding the switch, but quite suddenly, and exactly at the time of the listing switch.

[Figure 4 here]

As a caveat, we recognize that average trade size on particular exchanges may change for reasons other than a change in the amount of tape shredding. In particular, changes in average trade size on NYSE and AMEX are likely to be affected if the mix of large and small traders responds to the change of primary listing. Also, the other exchanges experienced changes in market share of trading volume, that may be associated with a change in the mix of traders transacting on those exchanges.

Table IV provides additional information on how the distribution of reported trade sizes changed on each exchange when the ETFs migrated. This table confirms that the change in the average trade size is largely due to changes in the number of 100-share trades relative the number of larger trades. When the ETFs were trading in Network B, we find that trades of 100 shares account for approximately $82 \%$ of all trades of these ETFs reported on Nasdaq, 95\% on Arca, and $96 \%$ on the National Exchange. After they migrated to Network A, these numbers drop to approximately 25\%,32\%, and 30\%. On these three exchanges, the huge decrease in the proportion of 100 share trades is offset by increases in the each of the other five trade-size buckets.

[Table IV here]

In the three months prior to November 30, 2005, we estimate that these 40 ETFs accounted for approximately $21 \%$ of all trades printed on Network B. While this was not 
quite as large an event as the departure of the QQQs, it was large enough that it had an economically significant effect on the marginal revenue per trade for the the securities remaining in Network B.

Table $\mathrm{V}$ reports what happened to the number of trades, trading volume, and average trade size for these securities, and table VI reports what happened to the distribution of trade sizes. As before, panel A of each table shows results based on three-month windows for all exchanges except Nasdaq and National and panel B shows results based on one-month windows surrounding the event. We find that when the 40 ETFs left Network B, average trade size declined significantly on Arca Ex, Nasdaq, and National. No significant change is observed on Chicago, and the results for Boston are inconsistent across the two window sizes. We also find a statistically significant increase in average trade size on AMEX. This confirms our prior results that AMEX, which did not have a rebate program, does not show evidence of tape shredding. Interestingly, we also find that the average trade size for Network B securities on NYSE declines significantly on the NYSE in the three-month samples. In the one-month samples, the change on NYSE is negative but not statistically significant. It should be noted that the NYSE trades only a small number of Network B securities. ${ }^{16}$

\section{[Table V here]}

The results in table VI indicate a modest increase in the percentage of 100-share trades on Nasdaq from $54.77 \%$ to to $57.27 \%$, on Arca Ex from $73.84 \%$ to $78.36 \%$, and on National from $69.64 \%$ to $72.2 \%$, for the one-month window.

\section{[Table VI here]}

In a parallel exercise, not reported here, we examined whether changes in trading patterns were observed when individual stocks switch from Amex to NYSE. Using the annual NYSE

\footnotetext{
${ }^{16}$ In results not shown, we found that the decrease in average trade size of non-migrating Network B securities on Arca Ex, Nasdaq, and National holds for ETFs and non-ETFs, holds across all deciles of trading volume, and does not appear to be conned to high-priced or low-priced stocks.
} 
Fact Books and press releases issued by the NYSE, we identified 164 stocks that switched from AMEX to NYSE between 1993 and 2005. In summary, we find a statistically signicant increase in the number of trades, but no statistical evidence that moving from AMEX to NYSE was associated with a change in trade size. We find that only one exchange (National) experienced a significant increase in average trade size when stocks migrated from AMEX to NYSE.

\section{Tape Shredding Rules}

In 2005 and 2006, the exchanges and NASD proposed (and the SEC approved) rules designed to reduce tape shredding. Specifically, these rules prohibit the unbundling of customer orders for reasons other than best execution.

In this section, we investigate whether the implementation of these rules had an appreciable effect on trading. Because these rules apply specifically to brokers who are handling customer orders on an agency basis, they would not affect order splitting by proprietary trading operations. Thus, looking at how trading activity changed when these rules became effective helps shed light on the extent to which our other results are driven by the behavior of brokers, as opposed to the activities of proprietary trading desks.

If the practice of order splitting by brokers was prevalent prior to these rules, and if these

rules were effective at reducing the practice, we would expect to see an increase in average trade size surrounding the implementation of these rules. If the response of the market to revenue allocation incentives is confined exclusively to proprietary trading operations, we would expect these tape shredding rules to have little or no effect.

In the appendix, we provide a table summarizing the date of the original proposal, the approval date and effective date for the tape shredding rules implemented by each of the Self-Regulatory Organizations. In some cases, the adopted rules reflect amendments filed after the original proposal date. In addition, we attempted to identify the date that these 
rules became effective, or the date that exchange members were informed of the rule. In the absence of any documentation of the effective date, we assume the effective date is the approval date.

To analyze the impact of these rules, we conduct two tests. First, we aggregate across all securities and examine whether total volume, number of trades, and average trade size were affected. Second, we perform a paired t-test, which examines stock-by-stock whether trading was affected, and then aggregates these individual comparisons into a single aggregate test statistic. If the tape shredding rules had an equal impact across all stocks, we would expect to see thus reflected in both tests. On the other hand, if the impact on the highest-volume stocks is disproportionately large, we would expect to see a more significant effect in the first test. Essentially, the first test is a value-weighted test, while the second places equal weights on all stocks.

In table VII, we report our results for trading activity on Network B securities. Panel A reports the results from the test based on aggregate trading activity. We find that when the tape shredding rule went into effect on NYSE/Arca, average trade size for Network B securities on that exchange increased by $87.4 \%$. Likewise, trade size increased on Nasdaq by $35.7 \%$ when NASD's rule became effective. These results suggest that tape shredding by brokers was most prevalent on those exchanges prior to the rule.

[Table VII here]

In contrast, we find a significant decline in average trade size of Network B securities traded on AMEX and the National Stock Exchange. It is not obvious why the implementation of a tape shredding rule should decrease average trade size. But since all of these exchanges implemented their rules at roughly the same time, it is possible that these rule changes induced a change in the equilibrium mix of large and small traders across exchanges.

Figure 5 shows a graph of average trade size on Network B securities on AMEX, Nasdaq, and NYSE/Arca surrounding the introduction of these tape shredding rules. The graph 
confirms that the increase in trade size on NYSE/Arca occurred rather suddenly on May 2, 2006, the second trading day after the rule adoption notice was circulated to members. The graph also indicates a sudden increase in average trade size on Nasdaq on May 25, 2006, the effective date of the rule. The decrease of average trade size on AMEX also occurred at this time.

[Figure 5 here]

Panel B of Table VII reports the results of our paired t-test. These results give quite a different picture. Based on this test, we observe no significant increases in average trade size, and even find a significant decrease on NYSE/ARCA. This suggests that the impact of the tape shredding rule was not uniform across all securities, but that the results of Panel A are driven by a relatively small number of securities. This is consistent with our earlier findings that switching from AMEX to NYSE had a significant impact on average trade size for ETFs but not for individual securities.

When we repeated both tests on Network A (NYSE-listed) securities (results not reported), we found no statistically significant increases in average trade size on any exchange. Indeed, these tests indicated a statistically significant decrease in average trade size on both NYSE/Arca and Nasdaq. That we find a different reaction in Network A and Network B reinforces our prior findings that tape shredding is more prevalent in Network B, where the revenue per trade is greater. We have no explanation for why trade size decreased on Network A. 


\section{New Allocation Rule}

In this section, we examine changes in trading activity surrounding April 1, 2007, when the new allocation formula went into effect. One of the aims of the formula change was to reduce the incentive for tape shredding. As mentioned above, the new formula allocates only $25 \%$ of the data revenue in proportion to the number of trades, with another $25 \%$ allocated in proportion to share volume and $50 \%$ in proportion to a measure of the aggressiveness with which the exchange quotes at the inside of the market. Thus, the immediate effect of the new formula was to reduce by about $75 \%$ the additional revenue allocated to the exchange when a large trade is split into multiple smaller trades.

Table VIII reports statistics summarizing the changes in trading activity surrounding the implementation of the new allocation formula. Based on a comparison of three months before and three months after April 1, 2007, we observe no increases in average trade size on any exchange surrounding April 1, consistent with our prior results that trade splitting is not rampant on Network A. No changes are observed on NYSE, NYSE Arca or Nasdaq 17 surrounding the implementation of the new formula, while there appears to have been a small but statistically significant decline in average trade size reported on National. We also observe significant decreases in the average size of Network A trades on some of the smaller exchanges. Given that these exchanges also experienced significant changes in total volume, it is somewhat difficult to know to extent to which these changes in average change size may be influenced by other changes in the market.

\section{[Table VIII here]}

The second panel of VIII reports the same statistics for Network B. We find that average trade size on Network B stocks increased by about $5 \%$ on NYSE/Arca, and decreased by $13 \%$ on AMEX. Both of these changes are statistically significant at the $1 \%$ confidence level. Again, the allocation formula appears to be associated with trade splitting on NYSE/Arca,

\footnotetext{
${ }^{17}$ At this point, we view this last result as preliminary, as we need to investigate further how trades reported to the exchanges' new Trade Reporting Facilities are reported in TAQ.
} 
but not on AMEX. In Table VIII, we find no significant change in the average size of Network B trades reported on Nasdaq or the National Stock Exchange. Interestingly, we do find an statistically significant increase in average trade size for Network B securities trading on NYSE.

We note that formula change on April 1 did not only decrease the incentive for tape shredding, it also increased the incentive for exchanges to quote aggressively. If some exchanges responded more than others to this incentive, those that are quoting most aggressively may have attracted more order flow, or a different kind of order flow as a result. Thus, the change in the allocation formula may have caused a change in average trade size for reasons other than changes in tape shredding.

Finally, we should note that although the changes in Network B activity reported for NYSE Arca and AMEX are statistically significant, the economic magnitude of these changes is smaller than for some of the other tests considered in this paper. Unlike some of the other events studied in this paper, where a simple visual examination of a graph reveals a sudden regime change on the event date, the effects documented in Table VIII for Network B stocks appear to have occurred gradually over time.

In this respect, our evidence in this section is somewhat weaker than in other sections. One possible reason for this is that when the new formula went into effect, the exchanges did not immediately alter their rebate programs, but continued to share revenue in proportion to the number of trades. To the extent that rebate programs are the key mechanism through which the allocation formula affects markets, we might expect the main impact of the new formula to occur only after the terms of these programs are modified to align the incentives of order flow providers with those of the exchange. 


\section{Conclusion}

In this paper, we have explored several facets of how the trading process is affected by the formulas used for allocating data revenue in proportion to the number of trades. Our results indicate that the old, proportional allocation rule had a strong influence under certain circumstances, but in other cases appears to have a minimal impact. The effect has been most severe where the revenue per trade is greatest (Network B), and on those exchanges that have developed mechanisms to exploit the formula. Moreover, our evidence indicates that the effects of the allocation rule are particularly concentrated in certain securities, such as certain Exchange Traded Funds. More research is needed to clarify the characteristics of securities that are associated with tape shredding. We have not investigated whether there is anything peculiar about ETFs that makes them particularly attractive for tape shredding, or whether the ETFs merely happened to be among the highest-volume securities trading in Network B.

We hope that by demonstrating that data revenue allocation has had an important influence on the trading process, this paper will stimulate further research on the nature of competition between exchanges. Three significant sources of revenues for the exchanges are listing fees, transaction fees, and data revenues. We would suggest that in the distant past, it was largely the case that these three revenue sources were closely tied to listing. That is, whichever exchange obtained the primary listing would also attract the dominant market share of transaction volume, and trades were reported where they were executed, so transaction fees and market data revenue were determined mostly by listing. But this has changed significantly since the mid 1990s, partially as a result of the economic forces and institutional developments explored in this paper. Today, there is vigorous competition for transaction volume, to the point that it is becoming less and less relevant where the stock is listed. This has especially been true of AMEX-listed securities, where the primary listing exchange is no longer one of the two largest trading venues. For Network A securities,

the New York Stock Exchange has also faced intense competition in the past few years. 
Apparently, primary listing no longer gives the listing exchange a significant advantage in the competition for order flow.

Similarly, we should note that a significant portion of all trading volume is either executed on ECNs or internalized, but this trading activity can only generate data revenue through a reporting channel. The research community must appreciate that there is an important distinction between competition among trading venues to execute trades and competition among plan participants to report trades that are executed off of the exchanges. The examples depicted in figures 1 and 2 illustrate that this becomes particularly important when an ECN that is unaffiliated with an exchange gains significant market share.

Along these lines, a notable development was the creation of trade reporting facilities. In the aftermath of the separation of Nasdaq and NASD in 2002, NASD created the Alternative Display Facility (ADF), giving Nasdaq's competitors a place to display quotes and report trades. ADF is a trade reporting facility-a channel for reporting trades executed on other venues-and is not associated with a platform for executing trades. More recently, four exchanges developed trade reporting facilities in 2007: NYSE, Nasdaq, Boston and National, of which NYSE and Nasdaq are actively used for trade reporting today. Prior to 2007, trades were reported to the tape using a single letter to designate the reporting channel. An observer could not distinguish by looking at the one-letter designation whether the trade was executed on the exchange or only reported there. Now, there is a two-letter designation that enables observers to make this distinction. ${ }^{18}$ This new information might create new opportunities for researchers to study off-exchange trading activity.

Another interesting topic that we do not address here is the extent to which the new allocation formula has led to greater depth at the NBBO. By assigning $50 \%$ of the revenue on the basis of quoting activity, the new formula should encourage more aggressive quoting. Further research in this area could shed light on whether the new formula succeeded in this

\footnotetext{
${ }^{18}$ For example, Nasdaq trades executed on Nasdaq are designated Q and trades reported on Nasdaq's trade reporting facility are designated DQ. Users of transaction-level databases such as NYSE's TAQ should note this change in February 2007.
} 
regard, and perhaps reveal other ways that the exchanges have responded in the face of this new incentive.

Other interesting research questions relating to equity markets are likely to emerge in the coming years. The equity trading industry is currently going through a period of rapid structural change, as a result of a confluence of many inter-related forces and trends. Among these are the demutualization of exchanges, the separation of the regulatory function from the exchanges, national and international consolidation, a blurring of the boundary between the securities industry and the commodities and futures industry, the Reg NMS order protection rule, new trading technologies that have significantly decreased the role of a physical trading floor, the increasing prevalence of "high frequency" and "low latency" trading, and the emergence of new "dark" trading platforms for institutional trading. As the industry moves towards a new equilibrium, new issues will arise and undoubtedly, a new generation of research will emerge. To the extent that market data revenue continues to be a major revenue source for exchanges, it is likely that data revenue will continue to play a significant role in shaping the industry. 


\section{References}

[1] Arnold, Tom, Philip Hersch, J. Harold Mulherin, and Jeffry Netter, 1999, Merging Markets, Journal of Finance 54, 1083-1107.

[2] Back, Kerry and Shmuel Baruch, 2007, Working Orders in Limit Order Markets and Floor Exchanges, Journal of Finance 62, 1589-1621.

[3] Barclay, Michael J. and Jerold Warner, 1993, Stealth Trading and Volatility: Which Trades Move Prices?, Journal of Financial Economics 34, 281-306.

[4] Battalio, Robert, Jason Green, and Robert Jennings, 1998, Does the Limit Order Routing Decision Matter?, Review of Financial Studies 15, 159-194.

[5] Battalio, Robert and Craig W. Holden, 2001, A Simple Model of Payment For Order Flow, Internalization, and Total Trading Costs, Journal of Financial Markets 4, 33-71.

[6] Bessembinder, Hendrik, 2003, Quote-Based Competition and Trade Execution Costs in NYSE Listed Stocks. Journal of Financial Economics, 70, 385-422.

[7] Bloomfield, Robert and O'Hara, Maureen, 1998, Does order preferencing matter?, Journal of Financial Economics 50, 3-37.

[8] Boulatov, Alex and Martin Dierker, 2007, Pricing Prices, working paper, University of Houston.

[9] Caglio, Cecilia and Andrea Pescatori, 2012, Competition Among Exchanges and Enforcement Policy, working paper.

[10] Chakravarty, Sugato, 2001. Stealth trading: Which traders trades move stock prices? Journal of Financial Economics 61, 289307.

[11] Foucault, Thierry, Odan Kadan, and Eugene Kandel, 2009, Liquidity Cycles and Make/Take Fees in Electronic Markets,Journal of Finance, forthcoming. 
[12] Madhavan, Ananth and Minder Cheng, 1997, In Search of Liquidity: Block Trades in the Upstairs and Downstairs Markets, Review of Financial Studies 10, 175-203.

[13] Choe, Hyuk and Oliver Hansch, 2006, Which Trades Move Stock Prices in the Internet Age? Working paper, Penn State University.

[14] Chordia, Tarun and Avanidhar Subrahmanyam, 1995, Market Making, The Tick Size and Payment-for-Order-Flow: Theory and Evidence, Journal of Business, 68, 543- 576.

[15] Chung, Kee H., Chairat Chuwonganant and D. Timothy McCormick, 2004, Journal of Financial Economics Vol 71(3), 581-612

[16] Foucault, Thierry and Christine A. Parlour, 2004, Competition for Listings, RAND Journal of Economics, The RAND Corporation, vol. 35(2), 329-355.

[17] Kugele, Lynn Phillips and Robert A. Wood(2006) Trade Shredding: SRO-Sponsored Payment for Order Flow, (with), Journal of Trading, (Winter 2007).

[18] Mulherin, J. Harold, Jeffrey M. Netter, and James Overdahl, 1991, Prices are Property: The Organization of Financial Exchanges from a Transaction Cost Perspective, Journal of Law and Economics 34:591-?.

[19] Parlour, C. and U. Rajan, 2003, Payment for Order Flow, Journal of Financial Economics, 68(3), 379411.

[20] Peterson, Mark A. and Erik R. Sirri, 2003, Order Preferencing and Market Quality on U.S. Equity Exchanges Review of Financial Studies vol16(2), 385-415 .

[21] Santos, Tano and Jose A. Scheinkman, 2001, Competition among Exchanges, Quarterly Journal of Economics, 116 (3), 1027-1061.

[22] Seppi Duane J. Equilibrium Block Trading and Asymmetric Information, 1990, The Journal of Finance, Vol. 45, No. 1, 73-94. 


\section{Appendix}

\section{Implementation Dates of Tape Shredding Rules}

\begin{tabular}{|l|c|c|c|}
\hline Exchange & Proposed & Approved & Effective \\
\hline Boston Stock Exchange & June 23, 2005 & August 26, 2005 & August 26, 2005 \\
New York Stock Exchange & September 9, 2005 & October 26, 2005 & November 10, 2005 \\
American Stock Exchange & November 1, 2005 & May 12, 2006 & May 12, 2006 \\
NASD & December 8, 2005 & February 24, 2006 & May 25, 2006 \\
Chicago Stock Exchange & January 24, 2006 & April 17, 2006 & April 17, 2006 \\
NYSE Arca & February 3, 2006 & April 24, 2006 & April 28, 2006 \\
National Stock Exchange & April 4, 2006 & May 24, 2006 & May 24, 2006 \\
\hline
\end{tabular}

\section{Table I: Impact of the QQQ Migration on Other Network B Stocks}

This table reports changes in trading volume, number of trades and average trade size for other Network B stocks surrounding the departure of the QQQ on December 1st 2004. Averages are computed for three-month windows before and after the switching date, based on data reported in TAQ. A test is performed to verify the significance of difference between the two periods. * denotes significance at the $5 \%$ level, ${ }^{* *}$ denotes significance at the $1 \%$ level.

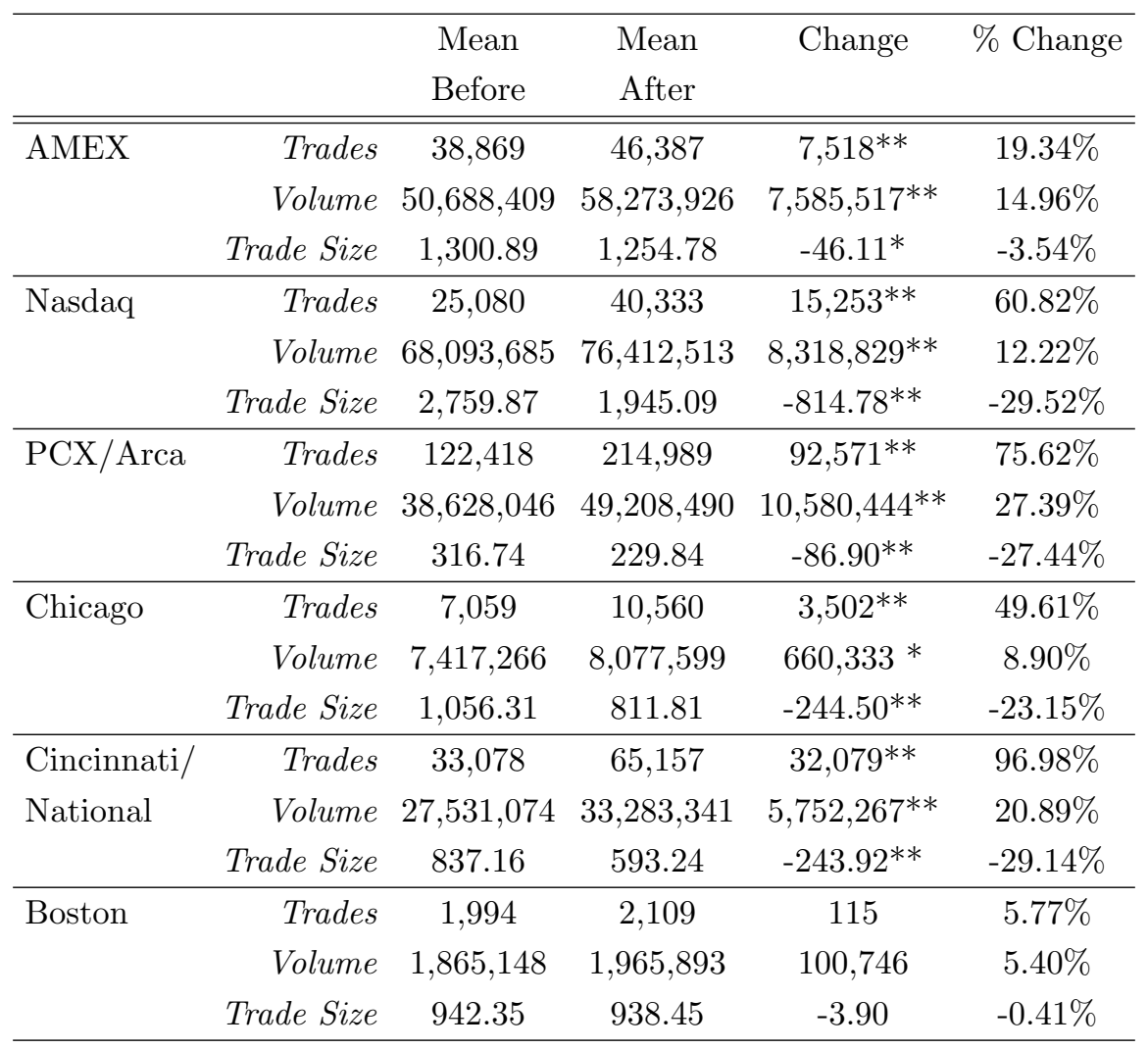




\section{Table II: Trade Distribution across Sizes Categories for Other Network B Stocks after the QQQ Migration}

This table reports the distribution of trades across different size categories for other Network B stocks surrounding the departure of the QQQ on December 1st 2004. Frequencies are computed for three-month windows before and after the switching date, based on data reported in TAQ. A test was performed to verify the significance of difference between the distributions for the two periods (numbers are not reported).

\begin{tabular}{lrcccccc}
\hline Share size & & 100 & $101-499$ & $500-999$ & $1000-2499$ & $2500-4900$ & $>5000$ \\
\hline \hline \multirow{2}{*}{ AMEX } & before & $27.41 \%$ & $28.53 \%$ & $17.01 \%$ & $16.46 \%$ & $5.29 \%$ & $5.3 \%$ \\
& after & $28.24 \%$ & $28.49 \%$ & $16.79 \%$ & $16.28 \%$ & $5.16 \%$ & $5.05 \%$ \\
\hline \multirow{2}{*}{ NASDAQ } & before & $24.18 \%$ & $25.49 \%$ & $17.25 \%$ & $21 \%$ & $4.87 \%$ & $7.21 \%$ \\
& after & $34.95 \%$ & $23.28 \%$ & $15.83 \%$ & $16.69 \%$ & $4.05 \%$ & $5.19 \%$ \\
\hline Arca-EX & before & $73.75 \%$ & $13.96 \%$ & $6.55 \%$ & $4 \%$ & $1 \%$ & $0.74 \%$ \\
& after & $84.37 \%$ & $8.53 \%$ & $3.44 \%$ & $2.58 \%$ & $0.65 \%$ & $0.42 \%$ \\
\hline Chicago & before & $22.79 \%$ & $31.38 \%$ & $18.34 \%$ & $18.67 \%$ & $5.17 \%$ & $3.66 \%$ \\
& after & $38.9 \%$ & $29.16 \%$ & $13.01 \%$ & $12.66 \%$ & $3.69 \%$ & $4.73 \%$ \\
\hline National & before & $25.04 \%$ & $27.36 \%$ & $26.31 \%$ & $16.28 \%$ & $3.07 \%$ & $1.94 \%$ \\
Cincinnati & after & $58.45 \%$ & $17.49 \%$ & $12.15 \%$ & $9.21 \%$ & $1.6 \%$ & $1.1 \%$ \\
\hline Boston & before & $18.79 \%$ & $29.17 \%$ & $20.83 \%$ & $24.41 \%$ & $4.61 \%$ & $2.19 \%$ \\
& after & $22.44 \%$ & $28.15 \%$ & $19.12 \%$ & $23.43 \%$ & $4.76 \%$ & $2.10 \%$ \\
\hline
\end{tabular}




\section{Table III: Changes in Trading Activity for ETFs moving from AMEX to NYSE}

This table reports the change in the mean number of trades, trading volume, and trade size, for 40 Exchange-Traded Funds that switched primary listing from AMEX to NYSE on November 30, 2005. Averages are computed for three-month windows (Panel A) and one-month window (Panel B) before and after the switching date, based on data reported in TAQ. A test is performed to verify the significance of difference between the two periods. ${ }^{*}$ denotes significance at the $5 \%$ level, ${ }^{* *}$ denotes significance at the $1 \%$ level.

\begin{tabular}{|c|c|c|c|c|c|}
\hline & & $\begin{array}{l}\text { Mean } \\
\text { before }\end{array}$ & $\begin{array}{l}\text { Mean } \\
\text { after }\end{array}$ & Change & \%Change \\
\hline \multirow[t]{3}{*}{ NYSE } & Trades & 420 & 7,440 & 7,020 & $1671 \%$ \\
\hline & Volume & $1,393,634$ & $14,371,598$ & $12,977,964 * *$ & $931.23 \%$ \\
\hline & Trade Size & $3,324.03$ & $1,929.76$ & $-1,394.27 * *$ & $-41.95 \%$ \\
\hline \multirow[t]{3}{*}{ AMEX } & Trades & 4,422 & 774 & $-3,648 * *$ & $-82.50 \%$ \\
\hline & Volume & $7,791,952$ & $2,668,449$ & $-5,123,503 * *$ & $-65.75 \%$ \\
\hline & Trade Size & $1,751.41$ & $3,486.00$ & $1,734.59 * *$ & $99.04 \%$ \\
\hline \multirow[t]{3}{*}{ Arca Ex } & Trades & 86,215 & 6,652 & $-79,563 * *$ & $-92.28 \%$ \\
\hline & Volume & $15,829,969$ & $10,643,374$ & $-5,186,595 * *$ & $-32.76 \%$ \\
\hline & Trade Size & 185.43 & $1,589.57$ & $1,404.14^{* *}$ & $757.25 \%$ \\
\hline \multirow[t]{3}{*}{ Chicago } & Trades & 925 & 1,115 & $190 * *$ & $20.50 \%$ \\
\hline & Volume & 500,307 & 748,239 & $247,933 * *$ & $49.56 \%$ \\
\hline & Trade Size & 541.80 & 686.03 & $144.22 * *$ & $26.62 \%$ \\
\hline \multirow[t]{3}{*}{ Boston } & Trades & 177 & 379 & $202 * *$ & $114.49 \%$ \\
\hline & Volume & 116,929 & 344,741 & $227,812 * *$ & $194.83 \%$ \\
\hline & Trade Size & 665.91 & 894.39 & $228.48^{* *}$ & $34.31 \%$ \\
\hline
\end{tabular}


Panel B: One-month window

\begin{tabular}{lrcccc}
\hline \multirow{5}{*}{ NYSE } & \multicolumn{1}{c}{$\begin{array}{c}\text { Mean } \\
\text { before }\end{array}$} & $\begin{array}{c}\text { Mean } \\
\text { after }\end{array}$ & Change & \%Change \\
& Trades & 459 & 6,097 & $5,638^{* *}$ & $1227.21 \%$ \\
& Volume & $1,522,320$ & $12,735,475$ & $11,213,155^{* *}$ & $736.58 \%$ \\
& Trade Size & $3,282.19$ & $2,076.60$ & $-1,205.58^{*}$ & $-36.73 \%$ \\
\hline AMEX & Trades & 4,347 & 842 & $-3,505^{* *}$ & $-80.63 \%$ \\
& Volume & $7,758,355$ & $2,454,860$ & $-5,303,495 * *$ & $-68.36 \%$ \\
& Trade Size & $1,777.07$ & $2,932.85$ & $1,155.78^{* *}$ & $65.04 \%$ \\
\hline \hline Nasdaq & Trades & 13,929 & 4,099 & $-9,830$ & $-70.57 \%$ \\
& Volume & $9,738,975$ & $11,290,020$ & $1,551,045^{* *}$ & $15.93 \%$ \\
& Trade Size & 714.53 & $2,788.66$ & $2,074.12^{* *}$ & $290.28 \%$ \\
\hline Arca Ex & Trades & 94,176 & 5,333 & $-88,843 * *$ & $-94.34 \%$ \\
& Volume & $16,777,725$ & $7,945,020$ & $-8,832,705 * *$ & $-52.65 \%$ \\
& Trade Size & 179.88 & $1,540.04$ & $1,360.16 * *$ & $756.13 \%$ \\
\hline National & Trades & 24,295 & 1,227 & $-23,068 * *$ & $-94.95 \%$ \\
& Volume & $3,713,590$ & $1,505,940$ & $-2,207,650 * *$ & $-59.45 \%$ \\
& Trade Size & 153.35 & $1,400.52$ & $1,247.17^{* *}$ & $813.28 \%$ \\
\hline Chicago & Trades & 865 & 791 & -73 & $-8.46 \%$ \\
& Volume & 474,850 & 630,780 & 155,930 & $32.84 \%$ \\
& Trade Size & 568.32 & 788.53 & 220.21 & $38.75 \%$ \\
\hline Boston & Trades & 134 & 192 & 58 & $43.10 \%$ \\
& Volume & 98,710 & 181,505 & $82,795 *$ & $83.88 \%$ \\
& Trade Size & 739.09 & 931.92 & $192.83 * *$ & $26.09 \%$ \\
\hline & & & & &
\end{tabular}




\section{Table IV: Trade Distribution across Sizes Categories for ETFs moving from}

AMEX to NYSE

This table reports the distribution of trades across different size categories for 40 Exchange-Traded Funds that switched primary listing from AMEX to NYSE on November 30, 2005. Frequencies are computed for three-month (Panel A) and one-month (Panel B) windows before and after the switching date, based on data reported in TAQ. A test was performed to verify the significance of difference between the distributions for the two periods (numbers are not reported).

Panel A: Three-months window

\begin{tabular}{lccccccc}
\hline Share size & & 100 & $101-499$ & $500-999$ & $1,000-2,499$ & $2,500-4,900$ & $>5,000$ \\
\hline \hline \multirow{2}{*}{ NYSE } & before & $11.67 \%$ & $19.52 \%$ & $15.41 \%$ & $22.41 \%$ & $11.64 \%$ & $19.34 \%$ \\
& after & $25.31 \%$ & $29.28 \%$ & $15.08 \%$ & $15.51 \%$ & $6.20 \%$ & $8.62 \%$ \\
\hline \multirow{2}{*}{ AMEX } & before & $30.21 \%$ & $31.01 \%$ & $14.38 \%$ & $12.96 \%$ & $4.34 \%$ & $7.10 \%$ \\
& after & $19.65 \%$ & $21.88 \%$ & $18.22 \%$ & $17.69 \%$ & $7.03 \%$ & $15.52 \%$ \\
\hline \multirow{2}{*}{ ARCA } & before & $95.41 \%$ & $2.23 \%$ & $0.73 \%$ & $0.86 \%$ & $0.32 \%$ & $0.45 \%$ \\
& after & $32.22 \%$ & $15.43 \%$ & $12.34 \%$ & $24.64 \%$ & $8.55 \%$ & $6.82 \%$ \\
\hline \multirow{2}{*}{ Chicago } & before & $35.38 \%$ & $34.55 \%$ & $17.09 \%$ & $10.33 \%$ & $1.71 \%$ & $0.94 \%$ \\
& after & $31.42 \%$ & $35.20 \%$ & $16.91 \%$ & $13.00 \%$ & $2.35 \%$ & $1.12 \%$ \\
\hline \multirow{2}{*}{ Boston } & before & $21.41 \%$ & $35.72 \%$ & $19.21 \%$ & $19.42 \%$ & $2.96 \%$ & $1.28 \%$ \\
& after & $14.63 \%$ & $31.79 \%$ & $22.72 \%$ & $23.01 \%$ & $5.08 \%$ & $2.77 \%$ \\
\hline
\end{tabular}

Panel B: One-month window

\begin{tabular}{lrrrrrrr}
\hline Share size & & 100 & $101-499$ & $500-999$ & $1000-2499$ & $2500-4900$ & $>5000$ \\
\hline \hline \multirow{2}{*}{ NYSE } & before & $12.9 \%$ & $19.8 \%$ & $17.93 \%$ & $21.19 \%$ & $9.53 \%$ & $18.65 \%$ \\
& after & $25.9 \%$ & $28.19 \%$ & $14.81 \%$ & $15.74 \%$ & $6.2 \%$ & $9.14 \%$ \\
\hline \multirow{2}{*}{ AMEX } & before & $29.47 \%$ & $31.5 \%$ & $15.12 \%$ & $12.56 \%$ & $4.19 \%$ & $7.16 \%$ \\
& after & $23.04 \%$ & $23.34 \%$ & $16.2 \%$ & $17.5 \%$ & $6.72 \%$ & $13.2 \%$ \\
\hline \multirow{2}{*}{ NASDAQ } & before & $79.58 \%$ & $10.12 \%$ & $4.11 \%$ & $4.12 \%$ & $0.87 \%$ & $1.21 \%$ \\
& after & $31.14 \%$ & $26.5 \%$ & $14.28 \%$ & $17.56 \%$ & $5.07 \%$ & $5.45 \%$ \\
\hline \multirow{2}{*}{ ARCA } & before & $94.48 \%$ & $3.24 \%$ & $0.72 \%$ & $0.86 \%$ & $0.32 \%$ & $0.39 \%$ \\
& after & $43.15 \%$ & $15.84 \%$ & $11.1 \%$ & $17.22 \%$ & $5.83 \%$ & $6.85 \%$ \\
\hline \multirow{2}{*}{ National } & before & $95.31 \%$ & $3.33 \%$ & $0.39 \%$ & $0.56 \%$ & $0.18 \%$ & $0.24 \%$ \\
\hline \multirow{2}{*}{ Chicago } & befter & $34.71 \%$ & $19.51 \%$ & $12.23 \%$ & $17.51 \%$ & $10.66 \%$ & $5.38 \%$ \\
& berter & $37.12 \%$ & $34.02 \%$ & $16.16 \%$ & $10.32 \%$ & $1.6 \%$ & $0.79 \%$ \\
\hline \multirow{2}{*}{ Boston } & before & $21.88 \%$ & $35.24 \%$ & $17.01 \%$ & $19.87 \%$ & $4.39 \%$ & $1.6 \%$ \\
& after & $12.72 \%$ & $31.11 \%$ & $23.2 \%$ & $24.66 \%$ & $5.75 \%$ & $2.57 \%$ \\
\hline
\end{tabular}


Table V: Impact of the ETF Migration from AMEX to NYSE on Other Network B Stocks

This table reports changes in number of trades, trading volume and average trade size for other Network B stocks when 40 Exchange-Traded Funds that switched primary listing from AMEX to NYSE on November 30, 2005. Averages are computed for three-month (Panel 1) and one-month (Panel B) windows before and after the switching date, based on data reported in TAQ. A test is performed to verify the significance of difference between the two periods. ${ }^{*}$ denotes significance at the $5 \%$ level, $* *$ denotes significance at the $1 \%$ level.

\begin{tabular}{|c|c|c|c|c|c|}
\hline & & $\begin{array}{l}\text { Mean } \\
\text { before }\end{array}$ & $\begin{array}{l}\text { Mean } \\
\text { after }\end{array}$ & Change & \%Change \\
\hline \multirow[t]{3}{*}{ NYSE } & Trades & 2,929 & 3 & $852^{* *}$ & $29.08 \%$ \\
\hline & Volume & $5,248,523$ & $5,145,867$ & $-102,656$ & $-1.96 \%$ \\
\hline & Trade Size & $1,779.06$ & $1,372.37$ & $-406.69^{* *}$ & $-22.86 \%$ \\
\hline \multirow[t]{3}{*}{ AMEX } & Trades & 52,273 & 63,017 & $10,745^{* *}$ & $20.55 \%$ \\
\hline & Volume & $55,182,144$ & $67,194,872$ & $12,012,728^{* *}$ & $21.77 \%$ \\
\hline & Trade Size & $1,052.86$ & $1,066.23$ & 13.38 & $1.27 \%$ \\
\hline \multirow[t]{3}{*}{ Arca Ex } & Trades & 237,620 & 293,828 & $56,208^{* *}$ & $23.65 \%$ \\
\hline & Volume & $76,862,241$ & $81,547,338$ & $4,685,097$ & $6.10 \%$ \\
\hline & Trade Size & 322.14 & 280.71 & $-41.44^{* *}$ & $-12.86 \%$ \\
\hline \multirow[t]{3}{*}{ Chicago } & Trades & 6,503 & 6,888 & 384 & $5.91 \%$ \\
\hline & Volume & $6,947,860$ & $7,501,587$ & $553,727^{*}$ & $7.97 \%$ \\
\hline & Trade Size & $1,091.26$ & 12.48 & $1.16 \%$ & \\
\hline \multirow[t]{3}{*}{ Boston } & Trades & 1,537 & 1,163 & $-374 * *$ & $-24.35 \%$ \\
\hline & Volume & $1,069,172$ & 732,992 & $-336,180 * *$ & $-31.44 \%$ \\
\hline & Trade Size & 700.42 & 632.17 & $-68.24 * *$ & $-9.74 \%$ \\
\hline
\end{tabular}


Panel B: One-month window

\begin{tabular}{|c|c|c|c|c|c|}
\hline & & $\begin{array}{l}\text { Mean } \\
\text { before }\end{array}$ & $\begin{array}{c}\text { Mean } \\
\text { after }\end{array}$ & Change & \%Change \\
\hline \multirow[t]{3}{*}{ NYSE } & Trades & 2,893 & 3,290 & $398^{*}$ & $13.74 \%$ \\
\hline & Volume & $4,591,530$ & $4,900,700$ & 309,170 & $6.73 \%$ \\
\hline & Trade Size & $1,594.71$ & $1,503.96$ & -89.75 & $-5.63 \%$ \\
\hline \multirow[t]{3}{*}{ AMEX } & Trades & 51,276 & 56,461 & $5,184^{*}$ & $10.11 \%$ \\
\hline & Volume & $53,058,798$ & $61,092,028$ & $8,033,230^{* *}$ & $15.14 \%$ \\
\hline & Trade Size & $1,035.20$ & $1,081.56$ & $46.35^{*}$ & $4.48 \%$ \\
\hline \multirow[t]{3}{*}{ Nasdaq } & Trades & 78,895 & 83,123 & 4,228 & $5.36 \%$ \\
\hline & Volume & $90,169,724$ & $86,515,230$ & $-3,654,494$ & $-4.05 \%$ \\
\hline & Trade Size & $1,138.93$ & $1,055.94$ & -82.99* & $-7.29 \%$ \\
\hline \multirow[t]{3}{*}{ Arca Ex } & Trades & 214,337 & 232,102 & 17,765 & $8.29 \%$ \\
\hline & Volume & $70,037,935$ & $68,024,040$ & $-2,013,895$ & $-2.88 \%$ \\
\hline & Trade Size & 326.64 & 297.89 & $-28.75^{*}$ & $-8.80 \%$ \\
\hline \multirow[t]{3}{*}{ National } & Trades & 83,585 & 84,824 & 1,239 & $1.48 \%$ \\
\hline & Volume & $31,207,780$ & $29,639,545$ & $-1,568,235$ & $-5.03 \%$ \\
\hline & Trade Size & 374.16 & 354.18 & $-19.98^{* *}$ & $-5.34 \%$ \\
\hline \multirow[t]{3}{*}{ Chicago } & Trades & 5,862 & 5,885 & 23 & $0.39 \%$ \\
\hline & Volume & $6,852,157$ & $6,762,733$ & $-89,424$ & $-1.31 \%$ \\
\hline & Trade Size & $1,169.23$ & $1,142.84$ & -26.39 & $-2.26 \%$ \\
\hline \multirow[t]{3}{*}{ Boston } & Trades & 1,224 & 1,018 & -206 & $-16.85 \%$ \\
\hline & Volume & 838,505 & 722,925 & $-115,580^{*}$ & $-13.78 \%$ \\
\hline & Trade Size & 687 & 707.53 & 20.53 & $2.99 \%$ \\
\hline
\end{tabular}




\section{Table VI: Trade Distribution across Sizes Categories for Other Network B Stocks after the ETF Migration from AMEX to NYSE}

This table reports the distribution of trades across different size categories for 40 Exchange-Traded Funds that switched primary listing from AMEX to NYSE on November 30, 2005. Frequencies are computed for three-month (Panel A) and one-month (Panel B) windows before and after the switching date, based on data reported in TAQ. A test was performed to verify the significance of difference between the distributions for the two periods (numbers are not reported).

Panel A: Three-months window

\begin{tabular}{lccccccc}
\hline Share size & & 100 & $101-499$ & $500-999$ & $1,000-2,499$ & $2,500-4,900$ & $>5,000$ \\
\hline \hline \multirow{2}{*}{ NYSE } & before & $26.98 \%$ & $23.75 \%$ & $15.8 \%$ & $19.29 \%$ & $5.99 \%$ & $8.19 \%$ \\
& after & $29.88 \%$ & $24.51 \%$ & $16.35 \%$ & $18.98 \%$ & $4.61 \%$ & $5.67 \%$ \\
\hline \multirow{2}{*}{ AMEX } & before & $32.04 \%$ & $29.02 \%$ & $16.39 \%$ & $14.19 \%$ & $4.36 \%$ & $3.99 \%$ \\
& after & $31.55 \%$ & $29.06 \%$ & $16.59 \%$ & $14.3 \%$ & $4.45 \%$ & $4.05 \%$ \\
\hline \multirow{2}{*}{ ARCA } & before & $75.18 \%$ & $10.72 \%$ & $7.22 \%$ & $5.06 \%$ & $1.12 \%$ & $0.7 \%$ \\
& after & $78.78 \%$ & $9.11 \%$ & $6.39 \%$ & $4.39 \%$ & $0.79 \%$ & $0.53 \%$ \\
\hline \multirow{2}{*}{ Chicago } & before & $22.92 \%$ & $27.64 \%$ & $21.34 \%$ & $19.91 \%$ & $5.02 \%$ & $3.17 \%$ \\
& after & $22.89 \%$ & $27.84 \%$ & $21.14 \%$ & $19.9 \%$ & $4.88 \%$ & $3.35 \%$ \\
\hline \multirow{2}{*}{ Boston } & before & $27.4 \%$ & $29.33 \%$ & $18.48 \%$ & $19.71 \%$ & $3.28 \%$ & $1.79 \%$ \\
& after & $29.38 \%$ & $29.59 \%$ & $17.77 \%$ & $19.06 \%$ & $2.91 \%$ & $1.29 \%$ \\
\hline
\end{tabular}

Panel B: One-month window

\begin{tabular}{|c|c|c|c|c|c|c|c|}
\hline Share size & & 100 & 101-499 & 500-999 & 1000-2499 & $2500-4900$ & $>5000$ \\
\hline \multirow[t]{2}{*}{ NYSE } & before & $28.66 \%$ & $24.33 \%$ & $14.87 \%$ & $19.08 \%$ & $5.43 \%$ & $7.63 \%$ \\
\hline & after & $28.43 \%$ & $25.44 \%$ & $14.98 \%$ & $19.84 \%$ & $4.77 \%$ & $6.54 \%$ \\
\hline \multirow[t]{2}{*}{ AMEX } & before & $31.41 \%$ & $29.86 \%$ & $16.55 \%$ & $13.96 \%$ & $4.32 \%$ & $3.9 \%$ \\
\hline & after & $31.27 \%$ & $28.77 \%$ & $16.61 \%$ & $14.6 \%$ & $4.6 \%$ & $4.14 \%$ \\
\hline \multirow[t]{2}{*}{ NASDAQ } & before & $54.77 \%$ & $18.01 \%$ & $11.82 \%$ & $10.37 \%$ & $2.55 \%$ & $2.49 \%$ \\
\hline & after & $57.27 \%$ & $16.65 \%$ & $11.05 \%$ & $10.16 \%$ & $2.45 \%$ & $2.42 \%$ \\
\hline \multirow[t]{2}{*}{ ARCA } & before & $73.84 \%$ & $11.76 \%$ & $7.44 \%$ & $5.2 \%$ & $1.04 \%$ & $0.72 \%$ \\
\hline & after & $78.36 \%$ & $9.38 \%$ & $6.33 \%$ & $4.36 \%$ & $0.93 \%$ & $0.64 \%$ \\
\hline National & before & $69.64 \%$ & $13.26 \%$ & $8.12 \%$ & $6.69 \%$ & $1.33 \%$ & $0.96 \%$ \\
\hline Cincinnati & after & $72.2 \%$ & $11.98 \%$ & $7.54 \%$ & $6.24 \%$ & $1.16 \%$ & $0.88 \%$ \\
\hline \multirow[t]{2}{*}{ Chicago } & before & $21.98 \%$ & $27.25 \%$ & $21.98 \%$ & $20.4 \%$ & $5.2 \%$ & $3.2 \%$ \\
\hline & after & $22.39 \%$ & $27.22 \%$ & $21.72 \%$ & $20.29 \%$ & $5.1 \%$ & $3.27 \%$ \\
\hline \multirow[t]{2}{*}{ Boston } & before & $27.06 \%$ & $28.95 \%$ & $18.09 \%$ & $20.76 \%$ & $3.54 \%$ & $1.61 \%$ \\
\hline & after & $25.93 \%$ & $28.49 \%$ & $17.89 \%$ & $22.36 \%$ & $3.74 \%$ & $1.59 \%$ \\
\hline
\end{tabular}




\section{Table VII: Impact of Tape-Shredding Rules on Network B Activity}

This table reports changes in trading activity for Network B stocks surrounding the implementation of Tape-Shredding Rules. Averages are computed for three-month windows before and after the switching date, based on data reported in TAQ. In Panel A, we perform a t-test on aggregate total volume, number of trades, and average trade size across all securities. A test is performed to verify the significance of difference between the two periods. In Panel B, we perform a paired t-test, which examines stock-by-stock the change in aggregate total volume, number of trades, and average trade size. ${ }^{*}$ denotes significance at the $5 \%$ level, $* *$ denotes significance at the $1 \%$ level.

\begin{tabular}{|c|c|c|c|c|c|}
\hline & & Mean & Mean & Change & $\%$ Change \\
\hline & & Before & After & & \\
\hline \multirow[t]{3}{*}{ AMEX } & Trades & 71,618 & 69,424 & $-2,194$ & $-3.16 \%$ \\
\hline & Volume & $77,379,446$ & $66,055,214$ & $-11,324,232^{* *}$ & $-17.14 \%$ \\
\hline & Trade Size & $1,077.47$ & 935.80 & $-141.68^{* *}$ & $-15.14 \%$ \\
\hline \multirow[t]{3}{*}{ Nasdaq } & Trades & 272,319 & 198,083 & $-74,237^{* *}$ & $-37.48 \%$ \\
\hline & Volume & $172,830,000$ & $172,970,000$ & 140,000 & $0.08 \%$ \\
\hline & Trade Size & 636.0211 & 863 & $227^{* *}$ & $26.32 \%$ \\
\hline \multirow[t]{3}{*}{ NYSE Arca } & Trades & 297,615 & 206,111 & $-91,505^{* *}$ & $-44.40 \%$ \\
\hline & Volume & $94,047,502$ & $124,290,000$ & $30,242,498^{* *}$ & $24.33 \%$ \\
\hline & Trade Size & 319.10 & 598.10 & $279.01^{* *}$ & $46.65 \%$ \\
\hline \multirow[t]{3}{*}{ National } & Trades & 5,892 & 4,563 & $-1,329^{* *}$ & $-29.13 \%$ \\
\hline & Volume & $7,784,495$ & $5,222,880$ & $-2,561,615^{* *}$ & $-49.05 \%$ \\
\hline & Trade Size & $1,313.95$ & $1,141.92$ & $-172.03^{* *}$ & $-15.16 \%$ \\
\hline \multirow[t]{3}{*}{ Chicago } & Trades & 7,870 & 8,242 & 372.23 & $4.52 \%$ \\
\hline & Volume & $8,515,021$ & $8,657,447$ & $142,426.00$ & $1.65 \%$ \\
\hline & Trade Size & $1,082.51$ & $1,047.10$ & -35.41 & $-3.38 \%$ \\
\hline \multirow[t]{3}{*}{ NYSE } & Trades & 3,746 & 4,366 & $620 * *$ & $14.20 \%$ \\
\hline & Volume & $6,279,232$ & $5,725,477$ & $-553,755$ & $-9.67 \%$ \\
\hline & Trade Size & $1,655.38$ & $1,329.90$ & $-325.48^{* *}$ & $-24.47 \%$ \\
\hline
\end{tabular}


Panel B: Paired Test (cont'd)

\begin{tabular}{|c|c|c|c|c|c|}
\hline & & \multirow{2}{*}{$\begin{array}{l}\text { Mean } \\
\text { Before }\end{array}$} & \multirow{2}{*}{$\begin{array}{l}\text { Mean } \\
\text { After }\end{array}$} & \multirow[t]{2}{*}{ Change } & \multirow[t]{2}{*}{$\%$ Change } \\
\hline & & & & & \\
\hline \multirow[t]{2}{*}{ AMEX } & Trades & $4,771.3$ & $4,606.0$ & -165.2 & $-3.5 \%$ \\
\hline & Volume & $5,137,897$ & $4,357,173$ & $-780,724^{* *}$ & $-15.2 \%$ \\
\hline 830 & Trade Size & $1,035.4$ & 953.3 & -82.1 & $-7.9 \%$ \\
\hline \multirow[t]{2}{*}{ Nasdaq } & Trades & $18,880.0$ & $13,851.3$ & $-5,028.7$ & $-26.6 \%$ \\
\hline & Volume & $12,050,496$ & $12,145,774$ & 95,278 & $0.8 \%$ \\
\hline 832 & Trade Size & $1,039.5$ & $1,136.4$ & 96.9 & $9.3 \%$ \\
\hline \multirow[t]{2}{*}{ NYSE Arca } & Trades & $21,255.6$ & $14,793.6$ & $-6,462.0$ & $-30.4 \%$ \\
\hline & Volume & $6,746,393$ & $8,961,243$ & $2,214,850$ & $32.8 \%$ \\
\hline 816 & Trade Size & 589.0 & 427.5 & $-161.5^{* *}$ & $-27.4 \%$ \\
\hline \multirow[t]{2}{*}{ National } & Trades & $5,311.3$ & $4,088.2$ & $1,223.1^{*}$ & $-23.0 \%$ \\
\hline & Volume & $7,186,970$ & $4,741,854$ & $-2,445,116^{* *}$ & $-34.0 \%$ \\
\hline 57 & Trade Size & $2,430.5$ & $1,745.2$ & -685.3 & $-28.2 \%$ \\
\hline \multirow[t]{2}{*}{ Chicago } & Trades & $2,579.5$ & 2576.2 & -3.2 & $-0.1 \%$ \\
\hline & Volume & $2,767,431$ & $2,713,497$ & 53,933 & $-1.9 \%$ \\
\hline 179 & Trade Size & $2,345.3$ & $1,699.0$ & -646.3 & $-27.6 \%$ \\
\hline \multirow[t]{2}{*}{ NYSE } & Trades & 4253.1 & 4606.0 & -165.2 & $-3.5 \%$ \\
\hline & Volume & $6,415,171$ & $6,375,579$ & $-39,592$ & $-0.6 \%$ \\
\hline 48 & Trade Size & 1648.3 & 1382.2 & $-266.1^{*}$ & $-16.1 \%$ \\
\hline
\end{tabular}




\section{Table VIII: Impact of New Allocation Formula}

This table reports changes in trading activity for Network B stocks (Panel A) and Network A stocks (Panel B) surrounding the implementation of the the new allocation formula that went into effect on april 1, 2007. Averages are computed for three-month windows before and after the event date, based on data reported in TAQ. A test is performed to verify the significance of difference between the two periods. ${ }^{*}$ denotes significance at the $5 \%$ level, $* *$ denotes significance at the $1 \%$ level.

\begin{tabular}{lrcccc}
\multicolumn{5}{c}{ Panel A:Impact on Network A Activity } \\
\hline \hline \multirow{2}{*}{ NYSE } & \multicolumn{1}{c}{ Before } & After & Change & \% Change \\
& Trades & $4,095,760$ & $4,002,172$ & $-93,588$ & $-2.28 \%$ \\
& Volume & $1,556,900,000$ & $1,515,400,000$ & $-41,500,000$ & $-2.67 \%$ \\
& Trade Size & 381.86 & 379.35 & -2.50 & $-0.66 \%$ \\
\hline Nasdaq & Trades & $2,615,671$ & $2,777,408$ & $161,737^{* *}$ & $6.18 \%$ \\
& Volume & $959,040,000$ & $1,029,700,000$ & $70,660,000^{*}$ & $7.37 \%$ \\
& Trade Size & 369.84 & 371.66 & 1.82 & $0.49 \%$ \\
\hline NYSE Arca & Trades & $1,545,748$ & $1,620,392$ & $74,644.00$ & $4.83 \%$ \\
& Volume & $311,630,000$ & $327,770,000$ & $16,140,000$ & $5.18 \%$ \\
& Trade Size & 202.45 & 202.10 & -0.35 & $-0.17 \%$ \\
\hline National & Trades & 34,778 & 68,921 & $34,143 * *$ & $98.17 \%$ \\
& Volume & $7,156,666$ & $10,655,736$ & $3,499,070 * *$ & $48.89 \%$ \\
& Trade Size & 236.55 & 153.83 & $-82.72 * *$ & $-34.97 \%$ \\
\hline Boston & Trades & 15,348 & 18,679 & $3,331 * *$ & $21.70 \%$ \\
& Volume & $3,211,427$ & $3,837,059$ & $625,632 *$ & $19.48 \%$ \\
& Trade Size & 210.97 & 202.95 & $-8 *$ & $-3.80 \%$ \\
\hline Chicago & Trades & $9,087.54$ & $6,969.07$ & $-2,118.47$ & $-23.31 \%$ \\
& Volume & $20,439,811.00$ & $16,566,329.00$ & $-3,873,482.00^{* *}$ & $-18.95 \%$ \\
& Trade Size & $8,570.39$ & $3,694.48$ & $-4,875.91^{* *}$ & $-56.89 \%$ \\
\hline AMEX & Trades & 744.37 & 792.3898 & 48.02 & $6.45 \%$ \\
& Volume & $1,008,793.00$ & $1,000,218.00$ & $-8,575.00$ & $-0.85 \%$ \\
& Trade Size & $1,341.36$ & $1,322.71$ & -18.65 & $-1.39 \%$ \\
\hline & & & & &
\end{tabular}


Panel B:Impact on Network B Activity

\begin{tabular}{lrcccc}
\hline \hline \multirow{2}{*}{ AMEX } & & Before & After & Change & \% Change \\
& Trades & 64,788 & 68,006 & 3,218 & $4.97 \%$ \\
& Volume & $40,391,182$ & $36,955,128$ & $-3,436,054^{*}$ & $-8.51 \%$ \\
& Trade Size & 626.65 & 544.60 & $-82.05 * *$ & $-13.09 \%$ \\
\hline \multirow{2}{*}{ Nasdaq } & Trades & 293,107 & 336,729 & $43,623 * *$ & $14.88 \%$ \\
& Volume & $164,170,000$ & $204,050,000$ & $39,880,000 * *$ & $24.29 \%$ \\
& Trade Size & 532.98 & 604.61 & $71.63 * *$ & $13.44 \%$ \\
\hline \multirow{2}{*}{ NYSE Arca } & Trades & 214,281 & 222,196 & $-11,815$ & $-5.51 \%$ \\
& Volume & $100,620,000$ & $108,800,000$ & $8,180,000$ & $8.13 \%$ \\
& Trade Size & 463.02 & 487.18 & $24.16 * *$ & $5.22 \%$ \\
\hline \multirow{2}{*}{ National } & Trades & 4,569 & 3,626 & $-943 *$ & $-20.65 \%$ \\
& Volume & $2,200,066$ & $1,727,573$ & $-472,493 *$ & $-21.48 \%$ \\
& Trade Size & 457.67 & 472.76 & 15.09 & $3.30 \%$ \\
\hline \multirow{2}{*}{ NYSE } & Trades & 6,769 & 4,254 & $-2,515 * *$ & $-37.15 \%$ \\
& Volume & $3,402,256$ & $2,623,261$ & $-778,995 * *$ & $-22.90 \%$ \\
& Trade Size & 510.03 & 620.80 & $110.77 * *$ & $21.72 \%$ \\
\hline
\end{tabular}


Figure 1:

Market Share of Network B Trades 2001-2006

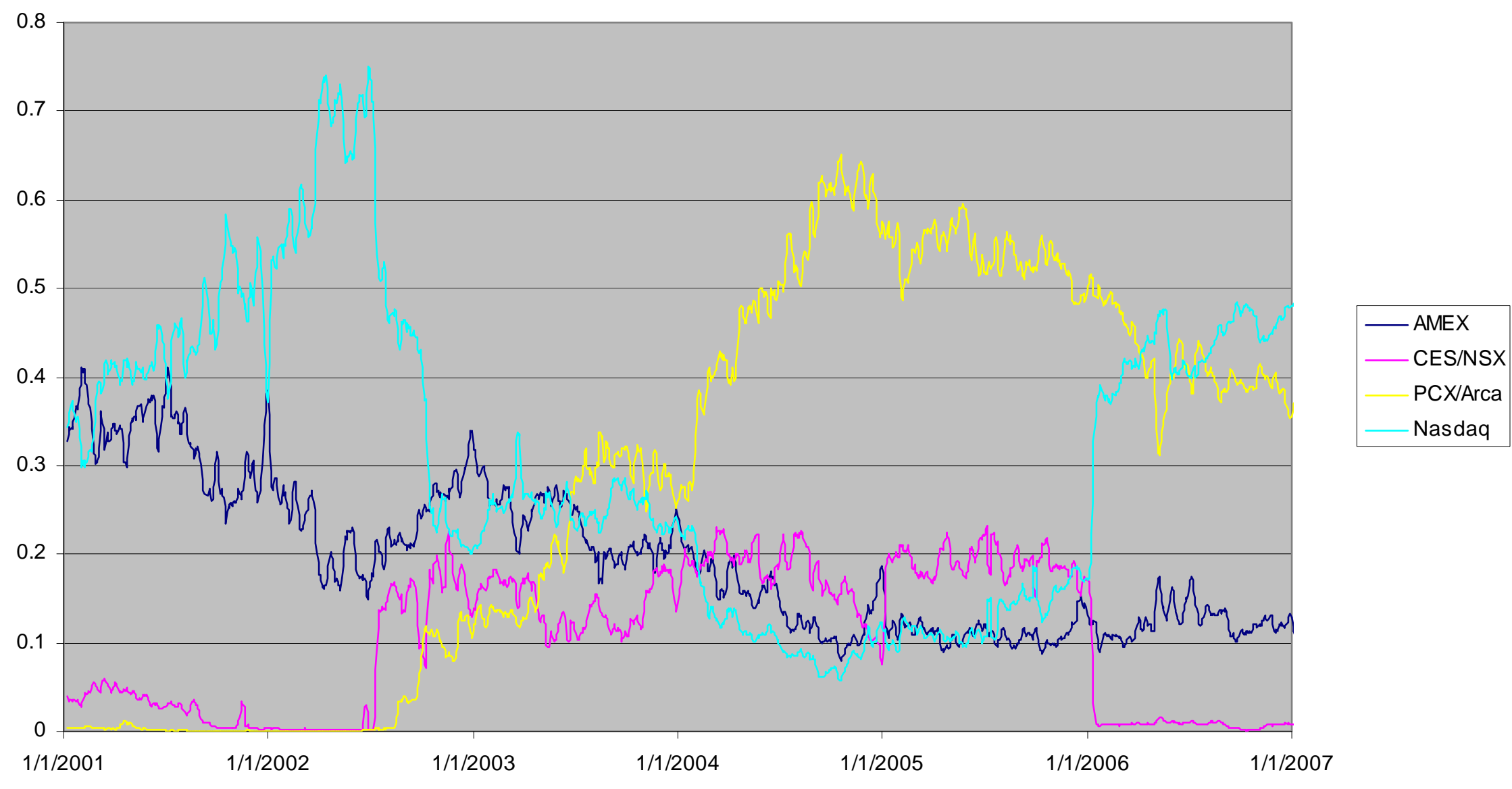


Figure 2:

Market Share of Network C Trades

2001-2006
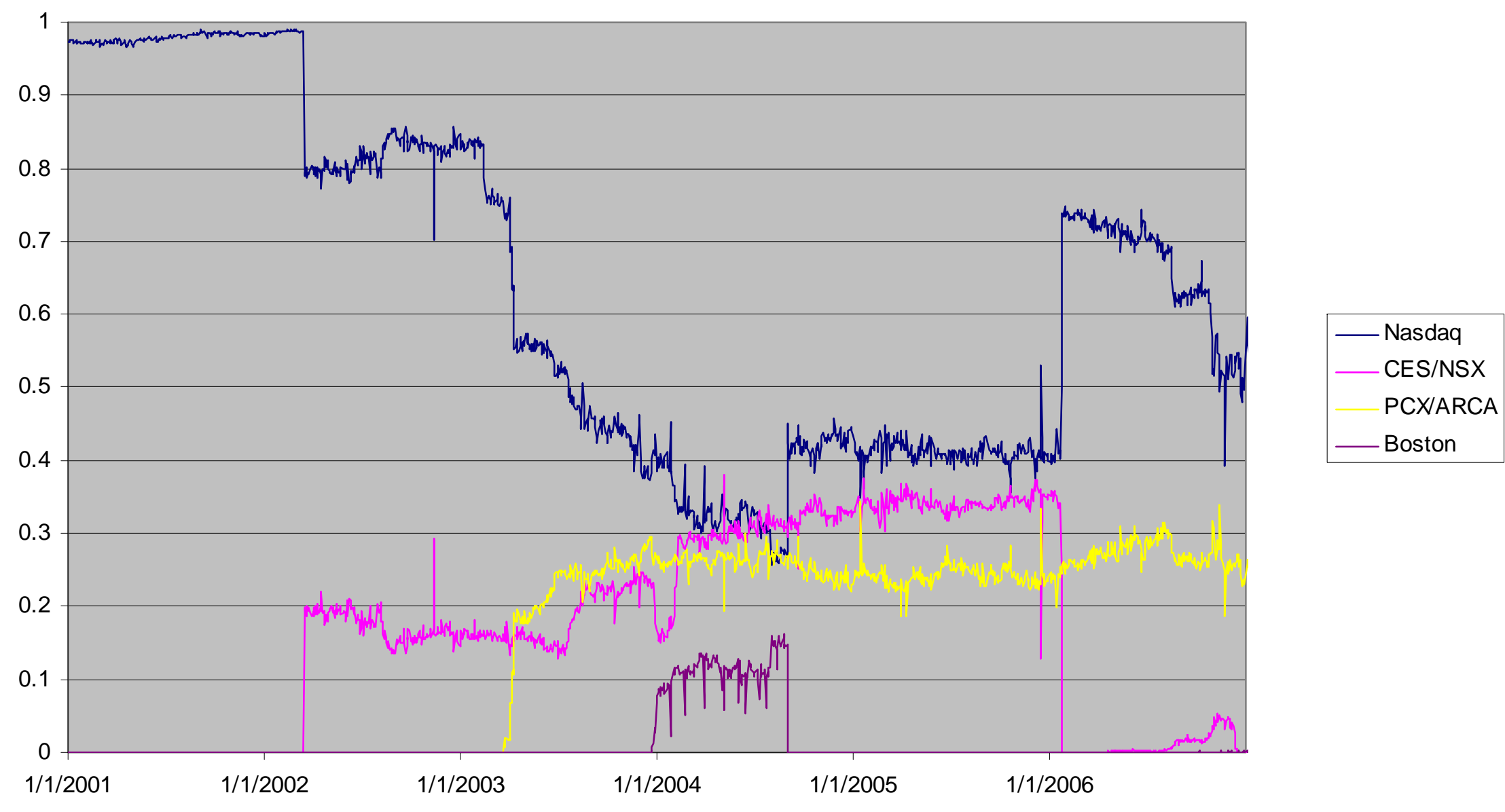
Figure 3:

Average Trade Size

Nasdaq 100 Tracking Stock (QQQ/QQQQ)

Surrounding Move from Network B to Network C

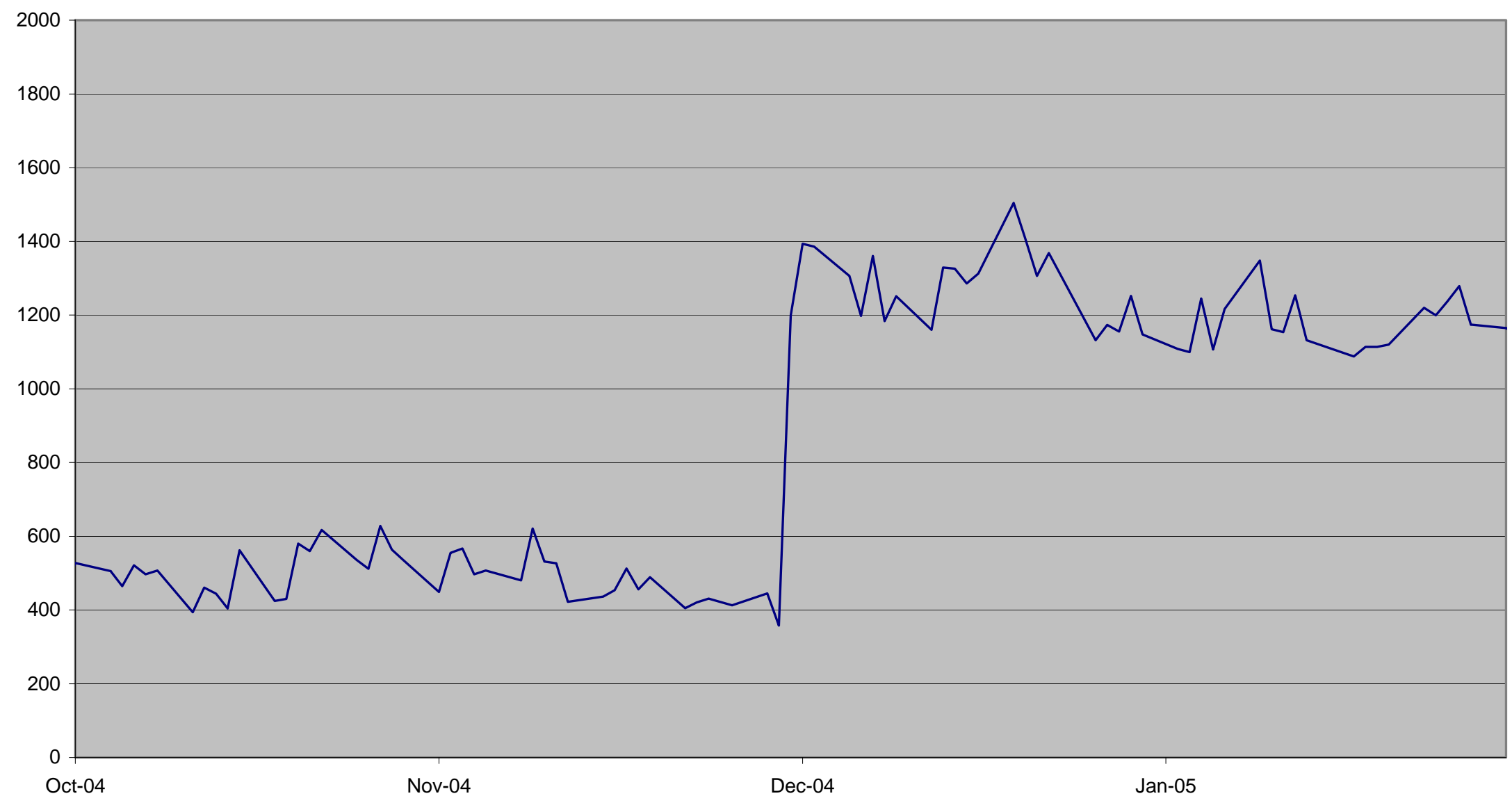


Figure 4:

Average Trade Size

40 iShares Exchange Traded Funds

Surrounding Move from Network B to Network A

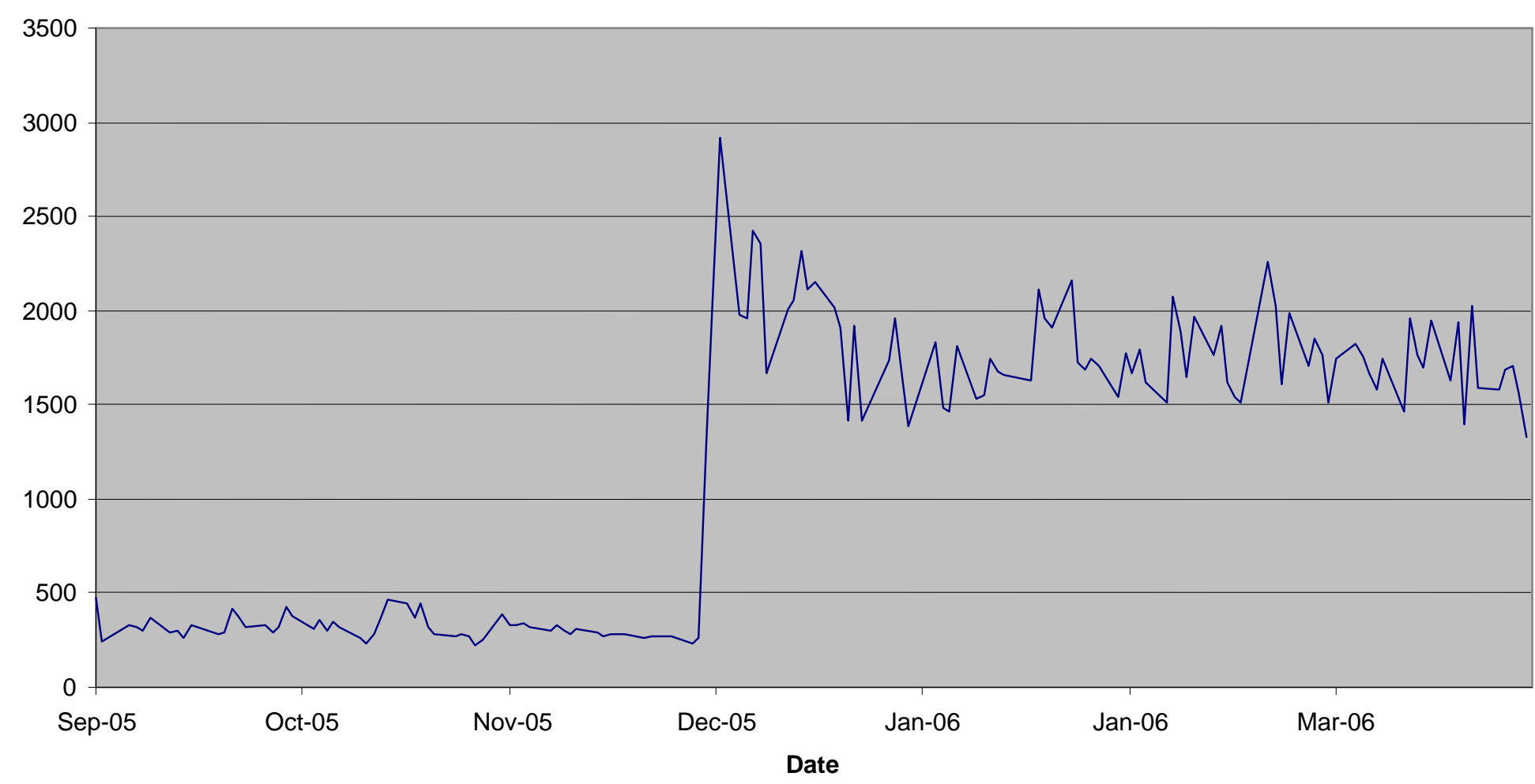


Figure 5:

Average Trade Size on Network B

Surrounding Introduction of Tape Shredding Rules

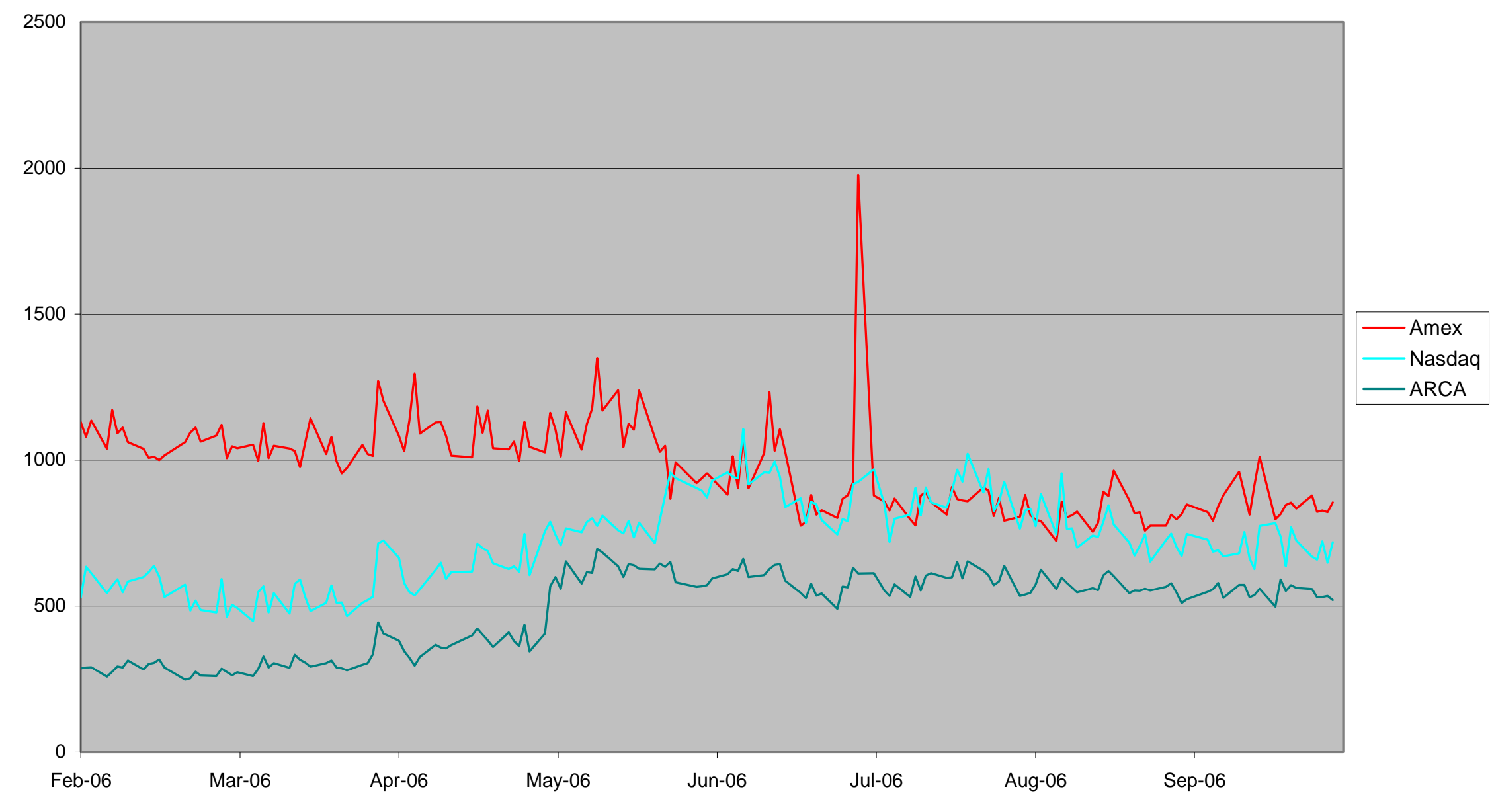

